\title{
Reproductive and behavioral effects of diisononyl phthalate (DINP) in perinatally exposed rats
}

Boberg, Julie; Christiansen, Sofie; Petersen, Marta Axelstad; Kledal, Thuri Seidler; Vinggaard, Anne Marie; Dalgaard, Majken; Nellemann, Christine Lydia; Hass, Ulla

\section{Published in:}

Reproductive Toxicology

Link to article, DOI:

10.1016/j.reprotox.2010.11.001

Publication date:

2011

Link back to DTU Orbit

Citation (APA):

Boberg, J., Christiansen, S., Petersen, M. A., Kledal, T. S., Vinggaard, A. M., Dalgaard, M., Nellemann, C. L., \& Hass, U. (2011). Reproductive and behavioral effects of diisononyl phthalate (DINP) in perinatally exposed rats. Reproductive Toxicology, 31(2), 200-209. https://doi.org/10.1016/j.reprotox.2010.11.001

\section{General rights}

Copyright and moral rights for the publications made accessible in the public portal are retained by the authors and/or other copyright owners and it is a condition of accessing publications that users recognise and abide by the legal requirements associated with these rights.

- Users may download and print one copy of any publication from the public portal for the purpose of private study or research.

- You may not further distribute the material or use it for any profit-making activity or commercial gain

- You may freely distribute the URL identifying the publication in the public portal 


\section{Accepted Manuscript}

Title: Reproductive and behavioral effects of Diisononyl phthalate (DINP) in perinatally exposed rats

Authors: Julie Boberg, Sofie Christiansen, Marta Axelstad, Thuri Seidler Kledal, Anne Marie Vinggaard, Majken Dalgaard, Christine Nellemann, Ulla Hass

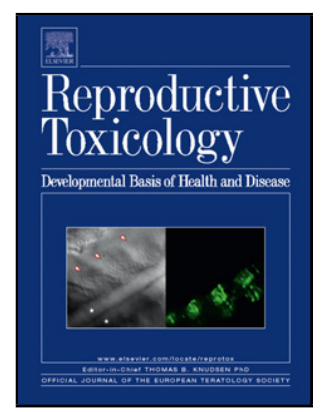

PII: S0890-6238(10)00325-4

DOI: doi:10.1016/j.reprotox.2010.11.001

Reference: RTX 6472

To appear in: $\quad$ Reproductive Toxicology

Received date: $\quad 27-8-2010$

Revised date: $\quad 20-10-2010$

Accepted date: $\quad$ 5-11-2010

Please cite this article as: Boberg J, Christiansen S, Axelstad M, Kledal TS, Vinggaard AM, Dalgaard M, Nellemann C, Hass U, Reproductive and behavioral effects of Diisononyl phthalate (DINP) in perinatally exposed rats, Reproductive Toxicology (2010), doi:10.1016/j.reprotox.2010.11.001

This is a PDF file of an unedited manuscript that has been accepted for publication. As a service to our customers we are providing this early version of the manuscript. The manuscript will undergo copyediting, typesetting, and review of the resulting proof before it is published in its final form. Please note that during the production process errors may be discovered which could affect the content, and all legal disclaimers that apply to the journal pertain. 
Reproductive and behavioral effects of Diisononyl phthalate (DINP) in perinatally exposed rats

Julie Boberg, Sofie Christiansen, Marta Axelstad, Thuri Seidler Kledal, Anne Marie Vinggaard, Majken Dalgaard, Christine Nellemann, Ulla Hass.

Division of Toxicology and Risk Assessment, National Food Institute, Technical University of Denmark, Mфrkhфj Bygade 19, DK-2860 Sфborg, Denmark.

Corresponding author: Julie Boberg, jubo@food.dtu.dk; Tel +45 3588 7560,fax +45 35887001 


\begin{abstract}
Diisononyl phthalate (DINP) is a plasticizer abundantly used in consumer products as a substitute for other plasticizers prohibited in certain products due to reproductive toxicity. As anti-androgenic effects of DINP are suspected, DINP effects on reproduction and sexually dimorphic behaviour
\end{abstract} were studied.

Pregnant Wistar rats were gavaged from gestation day 7 to postnatal day (PND) 17 with vehicle, $300,600,750$ or $900 \mathrm{mg}$ DINP/kg bw/day.

In fetal testes histopathological effects typical of phthalates were observed. In male offspring, DINP caused increased nipple retention, reduced anogenital distance, reduced sperm motility and increased sperm count. DINP affected spatial learning as female offspring performed better than controls and similarly to control males in the Morris Water Maze, indicating masculinization of behavior in DINP exposed females.

These results show that DINP causes anti-androgenic effects on reproductive development, though less potent than DEHP, DBP and BBP, and further safety evaluation of DINP appears warranted.

\title{
Keywords
}

Phthalate, behavior, rat, semen quality, anti-androgenic, toxicity 


\section{Introduction}

Several papers have suggested that the observed increasing incidences of testicular cancer, hypospadia, cryptorchidism and reduced semen quality in recent years may be caused by endocrine disrupting environmental chemicals having adverse effects on male reproduction [1]. Among the chemicals suspected of causing these effects in humans are some of the abundantly used phthalates found in plastics, paints and other materials. Human studies have indicated associations between maternal exposure to some phthalates and altered reproductive development in their infant sons. Di(2-ethylhexyl) phthalate (DEHP), butylbenzyl phthalate (BBP), di-n-butyl phthalate (DBP) and diisobutyl phthalate (DiBP), are known to induce adverse effects in the reproductive system of male rats. Perinatal exposure to certain phthalates leads to anti-androgenic effects such as reduced anogenital distance (AGD), retained nipples, hypospadias, undescended testes, epididymal agenesis and low sperm counts in male rats [2-4]. These four phthalates have been classified for reproductive toxicity in the European Union, and are therefore prohibited for use in cosmetics, some food contact materials, toys and childcare articles. Data for diisononyl phthalate (DINP) have not been considered sufficient for a classification, but DINP is currently prohibited in toys to be placed in the mouth by children under the age of 3 [5]. Due to the restrictions on other phthalates, DINP is now the main plasticizer in Europe and the use of DINP and diisodecyl phthalate (DiDP) has increased from $35 \%$ to $65 \%$ of plasticizer consumption in Western Europe from 1999 to 2008 [6].

Gray et al., 2000, found that $750 \mathrm{mg} / \mathrm{kg}$ bw per day of DINP induced nipple retention in males after perinatal oral exposure of Sprague Dawley rats, whereas the same doses of DEHP and BBP induced other malformations in male offspring, clearly indicating that DEHP and BBP are more potent reproductive toxicants than DINP [3]. Waterman et al., 2000, performed a two-generation study in rats showing no effect of dietary DINP exposure on fertility, whereas AGD and nipple retention was not examined in that study [7]. Since then, two dose-response studies have examined the effects of dietary DINP exposure in rats. Masutomi et al., 2003, found reduced maternal weight gain, reduced postnatal weight gain and reduced body and testis weights before puberty, and slight testicular histological effects in adulthood after perinatal dietary exposure to DINP, but did not see any alteration of AGD [8]. These effects were seen at 20,000 ppm (corresponding to 1200-2600 $\mathrm{mg} / \mathrm{kg}$ bw per day), but not at 4,000 and 400 ppm (approx. 400 and $40 \mathrm{mg} / \mathrm{kg}$ ). Lee et al., 2006, found reduced AGD and anogenital index (AGD divided by the cubic root of bodyweight) in all groups exposed via diet to DINP (40, 400, 4000 and $20000 \mathrm{ppm})$, whereas they did not detect any 
change in anogenital index with exposure to di-n-butyl phthalate (DBP) [9]. None of these studies examined semen quality parameters or effects on the developing nervous system.

A tight regulation of gonadal hormones is necessary for correct development of the central nervous system. Male and female rats are known to perform differently in a number of behavioral tests [10] and some of the same gender differences are seen in humans [11]. Female rats show higher spontaneous activity than males and have a higher preference for sweetened water, while males generally perform better than females in spatial learning tests [11-16]. Severe alterations in sex hormone levels, caused by either castration, ovariectomy or exposure to estradiol or testosterone during critical periods of development affects a variety of these sexually dimorphic behaviors [12;17-19]. However, only a few papers have been published on how developmental exposure to environmental anti-androgens may affect these behaviors. Neonatal exposure to the pesticide prochloraz, an androgen receptor antagonist and steroid synthesis inhibitor, has been shown to increase sweet preference in males, while no effect was seen on female sweet preference [20]. The anti-androgen cyproteronacetat, an androgen receptor antagonist, improved female maze learning [18]. No published studies are available on the effects of DINP or other phthalates on motor activity levels, spatial learning or sweet preference, and in line with our hypothesis of anti-androgenic effects of DINP, we wished to examine whether perinatal DINP exposure affects sexually dimorphic behavior in these tests.

Based on the indications of anti-androgenic effects of DINP and other phthalates and on the limited knowledge on how anti-androgens including phthalates may influence behavior, we aimed to investigate reproductive and behavioral effects of perinatal DINP exposure in rats. The current study was designed to provide improved dose-response data on the influence of DINP on androgen dependent endpoints. A small subfraction of litters were used for studying mechanisms of action in fetal testes, as some phthalates are known to reduce testosterone production in late gestation [2123]. Pregnant and lactating Wistar rats were gavaged with 0, 300, 600, 750 and $900 \mathrm{mg} / \mathrm{kg}$ bw per day of DINP from GD 7 to PND 17 and several hormone-sensitive endpoints were examined in fetuses, pups and in adult offspring, including semen quality parameters and sexually dimorphic behavior. 


\section{Materials \& Methods}

Test compounds: DINP, diisononyl phthalate, CAS No 28553-12-0, purity $99 \%$ was from Aldrich 37,666-3.

Animals and dosing: 80 time-mated Wistar rats (HanTac:WH, Taconic M\&B, Denmark, body weight approx. $200 \mathrm{~g}$ ) were supplied at day 3 of pregnancy. The animals were received in two blocks of 40 rats separated by one week. The day following mating was designated GD 1, and PND 1 was the day following birth. The dams were randomized into five groups of 16 with similar body weight distributions and housed in pairs until GD 21 under standard conditions. Semi-transparent plastic cages with pinewood bedding were situated in an animal room with controlled environmental conditions ( $12 \mathrm{~h}$ light-dark cycles with light starting at 9 p.m., light intensity 500 lux, temperature $22 \pm 2{ }^{\circ} \mathrm{C}$, humidity $55 \% \pm 5 \%$, ventilation 10 air changes per h). Food (Altromin Standard diet 1314) and tap water were provided ad libitum. The animals were dosed with vehicle (corn oil from Sigma), 300, 600, 750 or $900 \mathrm{mg}$ DINP/kg bw per day from GD 7 to PND 17. Animals were inspected for signs of general toxicity twice daily. These doses are comparable to doses used in other studies on DINP [3;7].

Subgroup 1: Caesarian section and investigation of fetal testosterone production and testicular

\section{histopathology}

On GD 21, 4 dams per group were anesthetized in $\mathrm{CO}_{2} / \mathrm{O}_{2}$ and decapitated, and fetuses were removed and decapitated. Testes were removed and sampled for histopathology, measurement of testosterone production ex vivo, or measurement of testosterone content. One or two testes per litter were placed in modified Davidson's fixative, and one testis per litter was placed in neutral buffered formaldehyde for histopathology and immunohistochemistry. Assessment of testosterone production ex vivo was performed on one testis from two pups per litter as described in [21] by incubating testes for 3 hours at $37^{\circ} \mathrm{C}$ in media containing $1 \mathrm{IU} / \mathrm{ml}$ of human chorion gonadotropin. Another testis per litter was placed in an empty tube and immediately frozen in liquid nitrogen and stored at $-80^{\circ} \mathrm{C}$ until analysis. Testosterone was extracted by two consecutive diethylether extraction procedures and stored at $-80^{\circ} \mathrm{C}$ until analysis.

Hormone analysis: Trunk blood from all males was collected with heparinized microfuge tubes and kept on ice. Pools of blood from each group was centrifuged at $4000 \mathrm{~g}$ for $10 \mathrm{~min}$ at $4^{\circ} \mathrm{C}$, and kept at $-80^{\circ} \mathrm{C}$ until analysis of testosterone content. Steroids were extracted from plasma samples by solid-phase extraction using IST Isolute C18 SPE columns of $100 \mathrm{mg}$. Testosterone content in incubation media, testes and plasma was analyzed with a Delfia time-resolved fluoroimmunoassay 
(PerkinElmer, Wallac Oy, Turku, Finland). The detection limit of the assay is $0.3 \mathrm{nM}$ and intraassay variability is reported to $5.5-6 \%$ by the supplier. Plasma LH was measured using the timeresolved fluorimetric assay (Delfia, Wallac OY, Turku, Finland), see[24] for specifications.

Histology: Sections of reproductive organs and thyroids were stained with haematoxylin and eosin for histopathological evaluation blinded to the observer.

\section{Subgroup 2: Pregnancy and postnatal development}

After birth (PND 1), dams and all live pups in the litter were weighed. Pups were sexed and the anogenital distance (AGD) was measured using a stereomicroscope. This distance is normally approximately twice as long in male as in female control offspring but can be reduced in males by anti-androgenic chemicals. At PND 13 all pups were weighted and examined for the presence of nipples/areolas, described as a dark focal area (with or without a nipple bud) located where nipples are normally present in female offspring. The nipples were counted and no distinction was made between the retention of an areola or a nipple. The number of nipples in female rats is normally 1213 versus zero in males. AGD and NR was recorded by the same technician blinded to exposure group.

Maternal pup retrieval, a test of interaction between mother and pups, was assessed on PND 1 in all dams. The dams were removed from their cage while three pups were moved from the nest to the corner of the cage diagonal to the nest, and the time the dam used to carry the pups back to the nest was recorded. The test was stopped if the dam had not retrieved her offspring within three minutes. At weaning (PND 21), pups were divided into two subgroups depending on their use for further studies. In all weaned offspring, age at sexual maturation was investigated by recording the day of vaginal opening in the females and cleavage of the balano-preputial skinfold in the males. The latter was done by observing when the prepuce, which is fused to the glans penis until the onset of puberty, could be fully retracted.

\section{Subgroup 2a: Reproductive organs and semen quality in adulthood:}

Tail blood was collected on PND 22 for Inhibin B analysis as described by [21].

Autopsy PND 90, males: 1-7 males per litter were anesthetized in $\mathrm{CO}_{2} / \mathrm{O}_{2}$ and blood samples were collected in heparinized tubes for hormone analysis. Males were examined for presence of nipples, penile malformations and testicular descent.

The following organs were excised and weighed: liver, kidney, adrenal, thyroid, right and left testis, left epididymis, seminal vesicle, ventral prostate, levator ani/bulbocavernosus muscle (LABC), 
bulbouretral gland. From all males one testis was fixed in modified Davidson's fixative for histopathology (alternately right and left testis). The contralateral testis was frozen for hormone analysis.

Testes for histopathology were processed after 24 hours and paraffin embedded and stained with hematoxylin and eosin, whereas all other organs were stored in formalin for later processing. Semen quality analysis was performed on 1-3 males per litter, and from further 1 to 3 males per litter, epididymides were fixed in formalin for histopathology. For semen quality analysis, the epididymides were removed and the cauda of the right epididymis was used for motility analysis. The cauda of the left epididymis was frozen in liquid nitrogen for later sperm count.

The right epididymis was trimmed of fat and cauda was placed in warm $\left(37^{\circ} \mathrm{C}\right)$ Medium 199 Hanks $\&$ Hepes (Invitrogen Life Technologies, Denmark), supplemented with $0.5 \%$ bovine serum albumin (Sigma Chemical Company, St. Louis, MO). Spermatozoa were obtained from the distal cauda where the tubular diameter is widest. Under the dissecting microscope, the cauda was held by forceps and several stabs were made into the tubules. The petri dish was placed in an incubator for 5 min. Cauda was removed and the sperm sample was diluted 10 times (in medium 199, supplemented with $0.5 \%$ bovine serum) and re-placed in the incubator for $10 \mathrm{~min}$, to allow dispersion of spermatozoa. Sperm samples were analyzed by computer-assisted sperm analysis (CASA; HTM-IVOS version 12 Hamilton Thorne Research, Beverly, MA). The parameters evaluated were percent motile and progressive sperm and sperm velocities. Cauda of the left epididymis was thawed at room temperature, trimmed of fat, weighed, and homogenized in $1 \mathrm{ml}$ Triton X-100. The homogenate was treated with ultrasonic sound and placed into a stain reaction vial containing DNA-specific fluorescent stain (Supra Vital IDENT Stain Kit, HTR). Sperm samples were placed in the HTM-IVOS. Samples were analyzed by CASA, counts were averaged, and the data were presented as number of sperm per gram cauda.

Autopsy PND 90, females. Females were autopsied on the day of estrus as determined by evaluation of vaginal smears. Uteri and ovaries were excised and weighed.

\section{Subgroup 2b: Behavior}

One or two male and female pups from each litter were weaned at PND 21 and used for behavioral testing. All animals from this group were sacrificed at approximately PND 200. The presence of malformations of external genitals and nipple retention in the males was investigated. 
Motor activity and habituation capability. Motor activity levels of the rat offspring were recorded at 4 weeks (PND 27/28) of age and in adults (PND 11-12 weeks old). At testing, the animals were placed individually in clean plastic cages without bedding, and the cages were placed in activity boxes with photocells that measured horizontal activity for $30 \mathrm{~min}$ as described in Axelstad et al., 2008 [25].

Morris maze Learning and memory. The testing in Morris water maze has been described earlier by Hass et al.1995, and Axelstad et al. 2008 and was carried out when the rats were 2-3 months of age [25;26]. The pool had a diameter of $220 \mathrm{~cm}$, and was situated in a laboratory measuring $4.5 \times 6$ $\mathrm{m}$ with a number of spatial cues on the surrounding walls (geometric shapes approximately one meter in height, posters and lockers), in order for the rats to triangulate their position. In the pool, a circular transparent platform was situated on a solid support and submerged $1 \mathrm{~cm}$ below the water surface, thus invisible from water level. The animals were tested in four daily trials using four different starting points along the rim of the pool. When the rats reached and climbed onto the platform, the trial was completed. If the animal failed to locate the platform within $60 \mathrm{~s}$, it was led to the platform and 60s were registered as time. A video-tracking device (Viewpoint video tracking system, Sandown Scientific, Middlesex, England) tracked the route of the animals, and the latency to find the platform, the swim length, and swim speed were used as endpoints. All tests were performed in dim lighting and the following scheme was used:

Learning: With the platform situated at the same place, the animals were trained in four trials per day for 5 consecutive days, until a stable performance was established.

Memory: Four weeks after the learning period, the animals were tested again with the platform still in the same position in the pool. The animals were given four trials on each of 2 consecutive days. New platform position (reversal learning and new learning): The day after the memory testing, the animals were tested in a reversal procedure (reversal learning) with the platform placed opposite to the original location. The following day, the platform was located in the centre of the maze (new learning). In both tests the animals were tested for four trials.

Sweet preference testing was performed at 4 months of age. The weeks before testing, the animals were housed one per cage, and habituated to drinking from two bottles with tap water. During the week of testing the animals were given a choice between tap water and water sweetened with $0.25 \%$ saccharin (Sigma-Aldrich). Position of the saccharin and water bottles were counterbalanced in each group to avoid position preferences. Each day the intake from both bottles was measured, and 
the bottles were refilled if needed. Body weights were registered in the same week and used for calculation of saccharin intake per $100 \mathrm{~g}$ body weight.

Radial arm maze. At the age of 5-7 months, the subgroup $2 \mathrm{~b}$ animals, were tested in a standard 8arm Radial Arm Maze (RAM). This test of spatial learning and memory ability consists of a maze elevated $90 \mathrm{~cm}$ above the floor with 8 arms radiating from a central area. At the end of each arm a reward is placed and photocells register the rat's movement in the maze as it searches for rewards. The testing procedure is described further in[25].

Statistical analysis. Data were examined for normal distribution and homogeneity of variance, and data were ln-transformed when relevant. In cases where normal distribution and homogeneity of variance could not be obtained by data transformation, a non-parametric Kruskall-Wallis test was used, followed by Wilcoxon's test for pair wise comparison.

Statistical analysis of the effect of DINP dosing on macroscopic lesions and histopathology, were done using Fisher's Exact Test.

When more than one pup from each litter was examined, statistical analyses was adjusted using litter as an independent, random and nested factor in ANOVA. Dunnett's test was performed to determine differences between treated and control group means. Data analysis of AGD included body weight as a covariate in the analysis, to correct for the relationship between body size and AGD. In the analysis of organ weights, body weight was used as a covariate, and in the analysis of pup weight at birth, PND 6 and PND 13 the number of animals per litter was used as a covariate. Generalized linear models (GLM) in combination with generalized estimating equations in order to account for the nested litter correlation analyzed the number of nipples. P-value adjustments were carried out by the ROM procedure, a powerful step-up procedure for protecting the global error rate $\alpha=5 \%$ [27]. Asterisks in tables and figures, indicate a statistically significant difference compared to controls $*$ : $\leq 0.05 ; * *: p<0.01$. Statistical analyses were done using the SAS procedure PROC GLM and PROC MIXED (SAS version 8, SAS Institute Inc, Cary, NC, USA). 


\section{Results}

\section{Subgroup 1: Caesarian section and investigation of fetal testosterone production and testicular} histopathology

Testicular histology was affected in all dose groups, with all examined animals affected in the two highest dose groups. Multinucleated germ cells were seen in some animals from the lowest dose group, and the percentage of affected animals increased with higher doses. In the two highest dose groups, most testes appeared to have an increased number of gonocytes with a central location in seminiferous chords, and chord diameters were significantly increased (Figure 1, Table 1). It should be noted that only one section from each of 5 to 7 testes representing 3 to 4 litters were investigated. A tendency towards reduced testicular testosterone production ex vivo was seen in the DINP exposed groups, but this was not statistically significant $(\mathrm{p}=0.08,0.11$ and 0.07 in the three highest dose groups, respectively) (Figure 2A). Testicular testosterone content was significantly reduced in the group exposed to $600 \mathrm{mg} / \mathrm{kg}$ bw per day of DINP ( $\mathrm{p}=0.044$ ) and a slight but not statistically significant reduction was seen in the highest dose group ( $\mathrm{p}=0.099$, Figure $2 \mathrm{~B})$. Plasma testosterone or LH levels were not significantly different between groups (Figure 2C and D). It should be noted that only a small number of samples were used for hormone analyses due to few litters $(n=3-4)$ available for caesarean section.

\section{Subgroup 2: Pregnancy and postnatal development}

Maternal body weight and weight gain during pregnancy was unaffected by treatment (Table 2). No changes in gestation length, postimplantation loss, litter size, sex ratio or perinatal loss were seen (Table 2).

Anogenital distance in male pups on PND 1 was reduced dose-dependently by DINP compared to controls (Table 3 and Figure 3). As the anogenital distance depends on the size of the animal, corrections for body weight were made by including birth weight as a covariate in the statistical analysis. Uncorrected anogenital distances were significantly lower at the three highest doses, but when including birth weight as a covariate the anogenital distance reduction was only statistically significant in males exposed to $900 \mathrm{mg} / \mathrm{kg}$ of DINP (Figure 3, Table 3). Also the "anogenital index", i.e. anogenital distance divided by the cubic root of the body weight was statistically 
significantly lower in the highest dose group. No statistically significant differences in birth weigths were observed, although DINP exposed males appeared slightly smaller (Table 3).

No change in female anogenital distance or birth weight was detected (Table 3).

Body weight at PND 13 was significantly reduced at $900 \mathrm{mg} / \mathrm{kg}$ bw per day in males and at 750 $\mathrm{mg} / \mathrm{kg}$ bw per day in females (Table 3). A statistically significant and dose-dependent increase in nipple retention in male pups was seen at 750 and $900 \mathrm{mg} / \mathrm{kg}$ bw per day, with a borderline significant increase in nipple retention at $600 \mathrm{mg} / \mathrm{kg}$ bw per day (adjusted $\mathrm{p}=0.058$ ) (Figure 3, Table $3)$.

Pup retrieval time, and age and weight at sexual maturation were unaltered by treatment (data not shown).

\section{Subgroup 2a: Reproductive organ studies and semen quality analysis in adulthood}

\section{Genital malformations and nipple retention at autopsy}

At PND 90 two control males had one nipple each and three males per group from the three highest dose groups had one to six nipples each. Of these, two animals from group DINP 600 and 750, respectively, had 4 and 6 thoracic nipples. There was no statistically significant difference between groups in the number of nipples or in anogenital distance at PND 90.

\section{Organ weights PND 90 males and females}

Weights of livers, thyroids and reproductive organs of males and females were not altered by treatment (Table 4). It was noted that one male from the DINP 600 group and one male from the DINP 750 group had small testes and epididymides.

\section{Histopathology PND 90}

Histology of male reproductive organs at PND 90 was not altered by DINP treatment (Table 5). Seminal vesicles showed few and insignificant findings and prostates showed more frequent alterations such as edema and leucocyte infiltration, but these alterations were also seen in controls and did not appear dose-related.

Testicular histology at PND 90 appeared unaffected although a few animals had small areas of tubular degeneration in areas of focal Leydig cell hyperplasia.

No consistent changes in the histology of adrenals, caput epididymis and thyroids were seen (data not shown). 
Semen quality PND 90

A dose-dependent reduction in the percentage of motile sperm was seen from $600 \mathrm{mg} / \mathrm{kg}$ bw per day (Figure 4). The percentage of motile sperm in the control group in the present study was well within the historical control range in our lab $[4 ; 25 ; 28]$. The percentage of progressive sperm was statistically significant in the 750 DINP group, in which one animal had very low sperm motility. This animal also had small testes and epididymides. When this animal was taken out of the statistical analysis, there were no longer significant effects of treatment on the percentage of progressive sperm. Sperm velocity parameters were not affected by DINP treatment but sperm count measured by IDENT was significantly higher in the highest dose group when analyzed both with and without the outlier mentioned above (Figure 4). This $17 \%$ increase in sperm count per gram cauda epididymis reflected a $9 \%$ increase in sperm counts per sample and a $7 \%$ decrease in cauda epididymis weight in the highest dose group compared to controls, although these differences were not statistically significant.

\section{Hormone analysis PND 22 and 90}

Inhibin B is a hormone produced in Sertoli cells and may be used as an indicator of Sertoli cell number and function and serum levels peak around PND 22 [29]. In DINP exposed males, Inhibin B levels at PND 22 were comparable to control levels (Table 4).

Mean testicular testosterone content on PND 90 in the highest dose group was $63 \%$ of control levels, but this was not statistically significant, and no other differences between groups were observed (Table 4).

\section{Subgroup 2b: Behavior}

Motor activity levels in young and adult offspring and radial arm maze performances were unaffected by DINP exposure in both male and female offspring (data not shown).

The results from the sweet preference test are shown in Figure 5. There was a statistically significant sex difference in the total saccharin intake per gram body weight $(\mathrm{p}=0.04)$, as control females consumed approximately $25 \%$ more than control males. The saccharin consumption was unaffected by DINP exposure in male offspring, but was significantly elevated in females in the 750 $\mathrm{mg} / \mathrm{kg}$ bw per day group $(\mathrm{p}=0.03)$. The high saccharin intake in this group was mainly caused by three females from three different litters in this group having an intake that was approximately $30 \%$ 
higher than the highest intakes among the other animals. As these values were plausible, they were not considered outliers. Elevated saccharin intake was, however, not seen in the highest dose group, and consequently the increased intake at $750 \mathrm{mg} / \mathrm{kg}$ bw per day might be a chance finding (Figure $5)$.

Results from the Morris Maze test are shown in figure $6(\mathrm{~A}+\mathrm{B})$. Male performance during both the learning and memory period was unaffected by DINP exposure (data not shown). At the end of the learning period (day 5) and on the first day of memory testing there was a marked sex difference, as swim length and latency to reach the platform were almost twice as long in control females compared to control males. Both swim length and latency to reach the platform in the control group in the present study was well within the historical control range, as other studies in our laboratory have shown very similar values in the control group (unpublished data). On the first day of the memory testing, female performances showed a dose-dependent improvement, which was statistically significant in the high dose group for both swim length $(\mathrm{p}=0.039)$ and latency $(\mathrm{p}=0.040)$. This improved performance in the high dose females made their values similar to the male values. The differences between DINP exposed and control females was not significant on the second day of the memory testing or when the platform was moved to a new position in the maze (data not shown). 


\section{Discussion}

Human exposure to the plasticizer DINP is increasing as DINP is used as a substitute for DEHP, which is classified as a reproductive toxicant in the European Union and therefore prohibited for use in certain products. The current study revealed that developmental DINP exposure reduces anogenital distance, increases nipple retention and reduces sperm motility in adulthood in male offspring and alters sexually dimorphic behavior in female offspring. Additionally, histological changes typical of phthalate exposure were seen in fetal testes and tendencies towards reduced fetal testosterone levels were seen, although the group sizes ( $n=3-4$ litters) for these investigations were small. These findings clearly indicate that DINP has similar effects on fetal testis histology, nipple retention and anogenital distance as those seen in numerous studies on DEHP and DBP [3;30;31], and further safety evaluation of the use of DINP is warranted. The current study further supports our previous study showing similar mechanisms of action (i.e. reduction of fetal testosterone production) of DINP as DEHP [21]. A comparison of different phthalates in the Hershberger assay for anti-androgenic action also found similar effects of DINP as DEHP, BBP and DBP [32]. In the current study, DINP reduced sperm motility and increased prepubertal nipple retention from $600 \mathrm{mg} / \mathrm{kg}$ bw per day, and a reduced AGD was seen in neonatal male rat pups at $900 \mathrm{mg} / \mathrm{kg}$ bw per day. These doses are high in comparison with DEHP, which increases nipple retention and reduces AGD from $10 \mathrm{mg} / \mathrm{kg}$ bw per day, and DBP which reduces AGD from $250 \mathrm{mg} / \mathrm{kg}$ bw per day [31;33-35], and DINP is thus less potent than DEHP and DBP.

The production of DEHP is decreasing in Europe while still being abundantly used worldwide.

However, as DEHP is mainly being replaced by DINP and diisodecyl phthalalate (DIDP), the use of DINP and DIDP now exceeds the use of DEHP threefold in Europe (ECPI homepage “phthtalates.com”). A human biomonitoring study showed a doubling of DINP exposure from 1988 to 2003, and with the recent change in use pattern from DEHP to DINP in Europe the risk of human DINP exposure may be rapidly increasing [36].

Previous studies have shown anti-androgenic effects of DINP at $750 \mathrm{mg} / \mathrm{kg}$ bw per day $[3 ; 21]$, whereas renal and hepatic effects have been seen at lower doses in chronic studies (summarized in [37]). Lee et al., 2006, reported reductions in anogenital index from $40 \mathrm{ppm}$ of DINP (approximately $5 \mathrm{mg} / \mathrm{kg}$ bw per day), but as they reported $\mathrm{n}=16$ to 47 , the applied statistics were probably based on single offspring instead of using litters as the statistical units [9]. An analysis of 
their data including consideration of litter effect would be required to determine the doses inducing statistically significant changes in anogenital index.

This is the first study to investigate effects of DINP on the development of sexually dimorphic behaviors. In the Morris water maze, which is a test investigating spatial learning and memory abilities, DINP exposed females showed a dose-dependent improvement, which was statistically significant in the highest dose group on the first day of memory testing. This improved performance in the high dose females made their performance similar to the male performance, and may therefore indicate masculinization of the brain in the high dose females. This was surprising as our own studies on female sexually dimorphic behavior in rats developmentally exposed to other antiandrogenic compounds including DEHP have not shown similar effects as presented here for DINP [39]. However, indications of masculinization of female learning behavior has been seen in previous studies after endocrine disruption during the critical periods of brain development, as treatment with both testosterone and the anti-androgen cyproteronacetat, an androgen receptor antagonist, improved female maze learning [17;18;38]. It is difficult to explain why both androgens and anti-androgens affect female maze learning in the same direction, but it appears that hormonal imbalance during the critical periods of brain development is sufficient to alter the default female outcome in a more masculine direction. Our study on DEHP showing no effect on female sexually dimorphic behaviors, however, included only one dose level of $100 \mathrm{mg} / \mathrm{kg}$ bw per day whereas the effect seen in this DINP study was statistically significant at $900 \mathrm{mg} / \mathrm{kg}$ bw per day. Effects of DINP on female behavior were not observed on the other test days in the Morris water maze, or in the other behavioral tests performed in the current study. Consequently, there is a need for further studies to elucidate the implications of the observed significant effect of DINP on female memory.

Saccharin intake appeared to be increased in females in the second-highest dose group, but not in the highest dose group and this may be a chance finding. A previous study of developmental exposure to a mixture of four anti-androgenic compounds (DEHP, Prochloraz, Vinclozolin and Finasteride) on female behavior has shown an increased intake of sweet water compared to control females [39]. If the observed increase in saccharin intake in DINP exposed animals is real, this finding further emphasizes that DINP acts similarly as other known anti-androgenic chemicals. However, as a high saccharin intake is regarded as a female characteristic in rats, this could be interpreted as polarization of sexual development (feminization of females), which is in contrast to the equalization of sexual differences observed with the other findings in the current study. It has 
previously been reported that anti-androgenic chemicals, e.g. the fungicide Prochloraz, can increase the sweet preference of males [20], but no changes in male sweet preference were found in the current study.

This is also the first study to investigate effects of DINP on semen quality. Interestingly, DINP dose-dependently reduced the percentage of motile sperm in the three highest dose groups, and a slight reduction in the percentage of progressive sperm was noted. Velocity parameters were not altered despite the observed reduction in the percentage of motile sperm. However, velocity parameters appeared rather insensitive as the one animal in the DINP 750 group with a very low sperm count and a low percentage of motile sperm had normal values of the four velocity parameters. In the highest dose group, a statistically significant increase in sperm counts measured as sperm per $\mathrm{g}$ cauda epididymis ( $\mathrm{p}=0.048$ ) was observed, but as sperm count per sample was slightly increased and cauda epididymis weight slightly reduced, this may reflect a change in epididymal development caused by DINP. In combination with the finding of reduced sperm motility, these data may indicate that DINP does not affect testicular sperm production, but may rather affect epididymal function and sperm maturation. As no changes in epididymal histopathology was observed, further analyses are needed to elucidate the effects of DINP on epididymis function and sperm maturation.

No changes in testicular histopathology were noted at PND 90 in the current study. Masutomi et al., 2003, reported slight Sertoli cell and spermatocyte degeneration together with debris in epididymal ducts in rats exposed to higher doses (1200-2600 mg/kg bw per day) of DINP [8]. A two-generation reproduction study on dietary DINP exposure showed no effects on fertility or testis histology, but did not examine semen quality parameters or anti-androgenic endpoints such as nipple retention and anogenital distance [7]. The lack of reproductive effects in that study is not in conflict with our finding of reduced sperm motility, as semen quality in rats may be affected without influencing fertility in rats [40;41]. In humans, on the other hand, reproduction is less robust than in the rat, and effects of DINP on sperm motility in humans may thus affect fertility although such an effect is not seen in rats [40;41].

DINP is a mixture of isomers, and two different CAS numbers for DINP exist covering variants of DINP produced by different processes and with different composition. DINP1 has CAS no $68515-$ 48-0 and DINP2 has CAS no 28553-12-0, and in the EU risk assessment, these different mixtures of isomers are evaluated together although differences in toxicity and physico-chemical properties 
may occur. The Waterman study used dietary DINP1 exposure throughout life while we studied perinatal exposure to DINP2 by gavage. Overall, the effects of DINP1 and DINP2 do not appear to differ significantly, as this and other studies on DINP2 [8;9;21] reveals comparable effects to those seen with DINP1 in the study by Gray et al., 2000.

In the present study, four DINP exposed animals had permanent malformations such as epididymal and testicular dysgenesis and permanent nipples. One animal from each of the groups exposed to 600 and $750 \mathrm{mg} / \mathrm{kg}$ bw per day of DINP had very small testes and epididymides. Additionally, two other males exposed to 600 and $750 \mathrm{mg} / \mathrm{kg} /$ day of DINP, had 4 and 6 thoracic nipples, respectively. These findings are comparable to the results reported in a study by Gray et al., 2000, in SpragueDawley rats. They reported malformations (permanently retained nipples and testicular and epididymal abnormalities) in 4 of 52 male pups from 3 of 14 litters exposed to $750 \mathrm{mg} / \mathrm{kg}$ bw per day of DINP [3]. In our study in Wistar rats, we examined 35, 18 and 22 males from 10, 7 and 8 litters in the three dose groups exposed to 600,750 and $900 \mathrm{mg} / \mathrm{kg}$ bw per day. Thus, the incidence of permanent malformations was slightly lower in our study (4 of 75 males exposed to $600 \mathrm{mg} / \mathrm{kg}$ or more, and 2 of 40 males exposed to $750 \mathrm{mg} / \mathrm{kg}$ or more) than in the study by Gray et al., 2000, (4 of 52 males exposed to $750 \mathrm{mg} / \mathrm{kg}$ ). Similarly, our comparable studies with DEHP in Wistar rats have shown that late adverse reproductive effects (i.e. testicular and epididymal abnormalities) are seen only in a subgroup of animals, whereas the majority of animals appear to regain full function also after DEHP exposure [4]. In the paper by Gray et al., 2000, the same dose of DEHP and BBP (750 mg/kg bw/day) induced a notably higher incidence of malformations including nipples, cleft phallus, hyperspadias, and agenesis of reproductive organs in male offspring than DINP did, showing that DINP is a less potent reproductive toxicant than DEHP and BBP [3].

No permanent changes in AGD were detectable, but as DINP appears to be a weaker anti-androgen than other phthalates, only slight alterations in adult AGD would be expected for DINP. Permanent changes of AGD have been observed in studies with more potent anti-androgens such as the herbicide linuron [42]. In that paper, BBP decreased AGD in the neonatate and not in the adult. Only when rats were exposed to BBP and linuron in combination, a the reduction in AGD observed in neonates persisted to adulthood [42]. However, the transient nature of the changes in AGD, nipple retention and testicular effects observed with DINP should not lead to the misinterpretation that these effects are unimportant. On contrary, the association of these early markers of endocrine disruption with adverse effects such as permanent malformations and disruption of the reproductive 
system has been shown in several studies [30;42-44] including the current study showing permanent alterations of semen quality and sexually dimorphic behavior.

Our own previous data showed reduction of fetal testicular testosterone level and -production at $750 \mathrm{mg} / \mathrm{kg}$ bw per day of DINP, and accumulative effects with combined exposure to DEHP [21]. In the current study, effects of DINP on fetal testosterone was only borderline significant, probably due to the small number of litters sampled for these endpoints. In both studies, changes in fetal testicular histopathology were observed, i.e. presence of multinucleated germ cells and enlarged seminiferous chords with centrally located gonocytes [45]. These changes are also seen with fetal exposure to DEHP and DBP, and these abnormalities show certain parallels to human testis cancer and the human testicular dysgenesis syndrome [46;47]. Further immunohistochemical analyses on fetal testes from the combination study on DEHP and DINP revealed that DINP reduced staining intensity for the steroidogenic factors StAR, P450scc and CYP17 in a similar manner as DEHP [48]. This indicates that DINP has a similar mechanism of action as DEHP and DBP, as the reduction of factors involved in steroid synthesis leads to reduced fetal testosterone levels as shown in several studies [49-51].

In contrast to our study, Adamsson et al., 2009, found no change in testosterone production of fetal testes at GD 19 after exposure to 250 and $750 \mathrm{mg} / \mathrm{kg}$ bw per day of DINP from GD 13 to 17 [52]. In fact, they found increased mRNA levels of P450scc and Insl3, genes that are known to be reduced by other phthalates and that are likely involved in the anti-androgenic effects of these compounds [52]. This discrepancy between the results of the current study and the results reported by Adamsson et al., 2009, may be due to the fact that their study included a recovery period of two days between the last dosing and the time of examination. As the authors describe in their discussion, it is possible that the detected increase in P450scc and Insl3 is a "rebound effect" due to low testosterone production at the time of dosing a few days earlier [52].

In summary, our findings of similar dose-related effects (nipple retention, reduction of anogenital distance, disruption of semen quality) of DINP as previously seen with DEHP and DBP clearly support that DINP is an anti-androgen and a reproductive toxicant, but is less potent than DEHP and DBP. Furthermore, our study supports the previously reported findings of persistent malformations in DINP exposed males [3]. So far, DINP has not been classified for reproductive or developmental toxicity in EU although previous studies have shown anti-androgenic and reproductive effects of DINP. This study presents further evidence for grouping DINP with the other anti-androgenic and 
reproductive toxic phthalates and will be useful for future risk assessments of DINP. This study also provides new knowledge on effects on sexually dimorphic behaviors indicating masculinization of behavior in DINP exposed females.

In conclusion, a NOAEL of $300 \mathrm{mg} / \mathrm{kg}$ bw per day for reproductive toxicity and anti-androgenic effects can be set. As the use of DINP is currently increasing, it may be anticipated that the antiandrogenic effect of DINP can be of importance for adverse endocrine disrupting and reproductive effects in humans, particularly as individuals are exposed to DINP in combination with several other anti-androgenic compounds present in the environment [53]. 


\section{Funding}

This work was supported by the EU project EDEN (QLK4-CT-2002-0603) and a grant from Nordic Council of Ministers.

\section{Acknowledgements}

Lillian Sztuk, Birgitte Møller Plesning, Bo Herbst, Dorte Hansen, Heidi Letting, Trine Gejsing, Ulla Baroudy, Kirsten Jarfelt and Vibeke Kjær are thanked for their excellent assistance. 


\section{Reference List}

[1] Skakkebaek NE, Rajpert-De Meyts E, Main KM. Testicular dysgenesis syndrome: an increasingly common developmental disorder with environmental aspects. Hum Reprod 2001; 16(5):972-978.

[2] Barlow NJ, Foster PM. Pathogenesis of male reproductive tract lesions from gestation through adulthood following in utero exposure to Di(n-butyl) phthalate. Toxicol Pathol 2003; 31(4):397-410.

[3] Gray LE, Jr., Ostby J, Furr J, Price M, Veeramachaneni DN, Parks L. Perinatal exposure to the phthalates DEHP, BBP, and DINP, but not DEP, DMP, or DOTP, alters sexual differentiation of the male rat. Toxicol Sci 2000; 58(2):350-365.

[4] Jarfelt K, Dalgaard M, Hass U, Borch J, Jacobsen H, Ladefoged O. Antiandrogenic effects in male rats perinatally exposed to a mixture of di(2-ethylhexyl) phthalate and di(2-ethylhexyl) adipate. Reprod Toxicol 2005; 19(4):505-515.

[5] EU. Directive 2005/84/EC of the European Parliament and of the Council of 14 December 2005. Official Journal of the European Union L344, 40-43. 2005.

[6] ECHA. DINP Review Report. Evaluation of new scientific evidence concerning the restrictions contained in Annex XVII to regulation (EC) No 1907/2006 (REACH). Review of new available information for diisononyl phthalate (DINP). 2010.

[7] Waterman SJ, Keller LH, Trimmer GW, Freeman JJ, Nikiforov AI, Harris SB et al. Twogeneration reproduction study in rats given di-isononyl phthalate in the diet. Reprod Toxicol 2000; 14(1):21-36.

[8] Masutomi N, Shibutani M, Takagi H, Uneyama C, Takahashi N, Hirose M. Impact of dietary exposure to methoxychlor, genistein, or diisononyl phthalate during the perinatal period on the development of the rat endocrine/reproductive systems in later life. Toxicology 2003; 192(23):149-170.

[9] Lee HC, Yamanouchi K, Nishihara M. Effects of perinatal exposure to phthalate/adipate esters on hypothalamic gene expression and sexual behavior in rats. J Reprod Dev 2006; 52(3):343352.

[10] Hass U. The new OECD test guideline on developmental neurotoxicity study: status and the potential for detection of behavioural effects of neuroendocrine disrupters. Umweltbundesamt Texte 1998; 50:129-137.

[11] Roof RL, Stein DG. Gender differences in Morris water maze performance depend on task parameters. Physiology \& Behavior 1999; 68(1-2):81-86.

[12] Beatty WW. Gonadal hormones and sex differences in nonreproductive behaviors in rodents: Organizational and activational influences. Hormones and Behavior 1979; 12(2):112-163.

[13] Kaya H, Hany J, Fastabend A, Roth-Härer A, Winneke G, Lilienthal H. Effects of Maternal Exposure to a Reconstituted Mixture of Polychlorinated Biphenyls on Sex-Dependent 
Behaviors and Steroid Hormone Concentrations in Rats: Dose-Response Relationship. Toxicol Appl Pharmacol 2002; 178(2):71-81.

[14] MacLusky NJ, Naftolin F. Sexual differentiation of the central nervous system. Science 1981; 211(4488):1294-1302.

[15] Valenstein ES, Kakolewski JW, Cox VC. Sex Differences in Taste Preference for Glucose and Saccharin Solutions. Science 1967; 156(3777):942-943.

[16] Williams CL, Meck WH. The organizational effects of gonadal steroids on sexually dimorphic spatial ability. Psychoneuroendocrinology 1991; 16(1-3):155-176.

[17] Dawson JL, Cheung YM, Lau RT. Developmental effects of neonatal sex hormones on spatial and activity skills in the white rat. Biol Psychol 1975; 3(3):213-229.

[18] Joseph R, Hess S, Birecree E. Effects of hormone manipulations and exploration on sex differences in maze learning. Behav Biol 1978; 24(3):364-377.

[19] Zucker I. Hormonal determinants of sex differences in saccharin preference, food intake and body weight. Physiol Behav 1969; 4:595-602.

[20] Vinggaard AM, Christiansen S, Laier P, Poulsen ME, Breinholt V, Jarfelt K et al. Perinatal exposure to the fungicide prochloraz feminizes the male rat offspring. Toxicological Sciences 2005; 85(2):886-897.

[21] Borch J, Ladefoged O, Hass U, Vinggaard AM. Steroidogenesis in fetal male rats is reduced by DEHP and DINP, but endocrine effects of DEHP are not modulated by DEHA in fetal, prepubertal and adult male rats. Reprod Toxicol 2004; 18(1):53-61.

[22] Borch J, Axelstad M, Vinggaard AM, Dalgaard M. Diisobutyl phthalate has comparable antiandrogenic effects to di-n-butyl phthalate in fetal rat testis. Toxicol Lett 2006; 163(3):183190.

[23] Parks LG, Ostby JS, Lambright CR, Abbott BD, Klinefelter GR, Barlow NJ et al. The plasticizer diethylhexyl phthalate induces malformations by decreasing fetal testosterone synthesis during sexual differentiation in the male rat. Toxicol Sci 2000; 58(2):339-349.

[24] Haavisto AM, Pettersson K, Bergendahl M, Perheentupa A, Roser JF, Huhtaniemi I. A supersensitive immunofluorometric assay for rat luteinizing hormone. Endocrinology 1993; 132(4):1687-1691.

[25] Axelstad M, Hansen PR, Boberg J, Bonnichsen M, Nellemann C, Lund SP et al. Developmental neurotoxicity of propylthiouracil (PTU) in rats: relationship between transient hypothyroxinemia during development and long-lasting behavioural and functional changes. Toxicol Appl Pharmacol 2008; 232(1):1-13.

[26] Hass U, Lund SP, Simonsen L, Fries AS. Effects of prenatal exposure to xylene on postnatal development and behavior in rats. Neurotoxicology and Teratology 1995; 17(3):341-349. 
[27] Rom D. A sequentially rejective test procedure based on a modified bonferroni inequality. Biometrika 1990; 77:663-665.

[28] Taxvig C, Hass U, Axelstad M, Dalgaard M, Boberg J, Andeasen HR et al. Endocrinedisrupting activities in vivo of the fungicides tebuconazole and epoxiconazole. Toxicological Sciences 2007; 100(2):464-473.

[29] Sharpe RM, Turner KJ, McKinnell C, Groome NP, Atanassova N, Millar MR et al. Inhibin B levels in plasma of the male rat from birth to adulthood: effect of experimental manipulation of Sertoli cell number. J Androl 1999; 20(1):94-101.

[30] Barlow NJ, McIntyre BS, Foster PM. Male reproductive tract lesions at 6, 12, and 18 months of age following in utero exposure to di(n-butyl) phthalate. Toxicol Pathol 2004; 32:79-90.

[31] Christiansen S, Boberg J, Axelstad M, Dalgaard M, Vinggaard AM, Metzdorff S et al. Lowdose perinatal exposure to di(2-ethylhexyl) phthalate induces anti-androgenic effects in male rats. Reprod Toxicol 2010; 30(2):313-321.

[32] Lee BM, Koo HJ. Hershberger assay for antiandrogenic effects of phthalates. J Toxicol Environ Health A 2007; 70(15-16):1365-1370.

[33] Gray LE, Jr., Barlow NJ, Howdeshell KL, Ostby JS, Furr JR, Gray CL. Transgenerational effects of Di (2-ethylhexyl) phthalate in the male CRL:CD(SD) rat: added value of assessing multiple offspring per litter. Toxicol Sci 2009; 110(2):411-425.

[34] Ema M, Miyawaki E, Hirose A, Kamata E. Decreased anogenital distance and increased incidence of undescended testes in fetuses of rats given monobenzyl phthalate, a major metabolite of butyl benzyl phthalate. Reprod Toxicol 2003; 17:407-412.

[35] Zhang Y, Jiang X, Chen B. Reproductive and developmental toxicity in F1 Sprague-Dawley male rats exposed to di-n-butyl phthalate in utero and during lactation and determination of its NOAEL. Reprod Toxicol 2004; 18:669-676.

[36] Wittassek M, Wiesmüller GA, Koch HM, Eckard R, Dobler L, Müller J et al. Internal phthalate exposure over the last two decades - A retrospective human biomonitoring study. International Journal of Hygiene and Environmental Health 2007; 210(3-4):319-333.

[37] European Chemical Bureau. European Union Risk Assessment Report. Vol 35. Di"isononyl" phthalate (http://ecb.jrc.it). 2003.

[38] Roof RL. Neonatal exogenous testosterone modifies sex difference in radial arm and Morris water maze performance in prepubescent and adult rats. Behav Brain Res 1993; 53(1-2):1-10.

[39] Christiansen $\mathrm{S}$. PhD thesis: Effects of combined exposure to anti-androgens on development and sexual dimorphic behaviour in rats [ National Food Institute, Technical University of Denmark; 2009.

[40] Spielmann H. Reproduction and development. Environ Health Perspect 1998; 106 Suppl 2:571-576. 
[41] OECD. Guidance document on mammalian reproductive toxicity testing and assessment. OECD Environment, Health and Safety Publications. Series on Testing and Assessment. No. 43. 2008.

[42] Hotchkiss AK, Parks-Saldutti LG, Ostby JS, Lambright C, Furr J, Vandenbergh JG et al. A mixture of the "antiandrogens" linuron and butyl benzyl phthalate alters sexual differentiation of the male rat in a cumulative fashion. Biol Reprod 2004; 71(6):1852-1861.

[43] Christiansen S, Scholze M, Axelstad M, Boberg J, Kortenkamp A, Hass U. Combined exposure to anti-androgens causes markedly increased frequencies of hypospadias in the rat. Int J Androl 2008; 31(2):241-248.

[44] Foster PM, McIntyre BS. Endocrine active agents: implications of adverse and non-adverse changes. Toxicol Pathol 2002; 30(1):59-65.

[45] Hormonal and testicular effects of DINP and DEHP in fetal male rats. Poster at 13th European Testis Workshop, April 24-28, 2004, Dunblane, Scotland, UK. 2004.

[46] Fisher JS, MacPherson S, Marchetti N, Sharpe RM. Human 'testicular dysgenesis syndrome': a possible model using in-utero exposure of the rat to dibutyl phthalate. Hum Reprod 2003; 18(7):1383-1394.

[47] Ferrara D, Hallmark N, Scott H, Brown R, McKinnell C, Mahood IK et al. Acute and longterm effects of in utero exposure of rats to di(n-butyl) phthalate on testicular germ cell development and proliferation. Endocrinology 2006; 147(11):5352-5362.

[48] Boberg J. Endocrine disrupters affecting male rat reproductive development. PhD thesis, Technical University of Denmark. 2007.

[49] Borch J, Metzdorff SB, Vinggaard AM, Brokken L, Dalgaard M. Mechanisms underlying the anti-androgenic effects of diethylhexyl phthalate in fetal rat testis. Toxicology 2006; 223(12):144-155.

[50] Lehmann KP, Phillips S, Sar M, Foster PM, Gaido KW. Dose-dependent alterations in gene expression and testosterone synthesis in the fetal testes of male rats exposed to di (n-butyl) phthalate. Toxicol Sci 2004; 81(1):60-68.

[51] Shultz VD, Phillips S, Sar M, Foster PM, Gaido KW. Altered gene profiles in fetal rat testes after in utero exposure to di(n-butyl) phthalate. Toxicol Sci 2001; 64(2):233-242.

[52] Adamsson A, Salonen V, Paranko J, Toppari J. Effects of maternal exposure to diisononylphthalate (DINP) and 1,1-dichloro-2,2-bis(p-chlorophenyl)ethylene (p,p'-DDE) on steroidogenesis in the fetal rat testis and adrenal gland. Reprod Toxicol 2009; 28(1):66-74.

[53] Christiansen S, Scholze M, Dalgaard M, Vinggaard AM, Axelstad M, Kortenkamp A et al. Synergistic disruption of external male sex organ development by a mixture of four antiandrogens. Environ Health Perspect 2009; 117(12):1839-1846. 


\section{Figures}

Figure 1: Testicular histopathology at GD 21 in male rat fetuses exposed to 0 or $750 \mathrm{mg}$ DINP/kg bw per day from GD 7 to GD 21. Multinucleated gonocytes (>) were present in testes of DINPexposed animals. Gonocytes were located centrally in the enlarged seminiferous chords. Original magnification 20x.

Figure 2: Testosterone levels at GD 21 in male rat fetuses exposed to 0, 300, 600, 750 or $900 \mathrm{mg}$ DINP/kg bw per day from GD 7 to GD 21. A) Testicular testosterone production ex vivo ( $\mathrm{n}=3-4$ litters, 2 testes per litter), B) Testicular testosterone content ( $\mathrm{n}=3-4$ litters, 1-2 testes per litter), C) Plasma testosterone ( $n=3-4$ samples pooled from each litter), D) Plasma LH ( $n=2-3$ samples, each are pools of plasma from 1-2 litters). Mean + SEM, asterisks indicate a statistically significant difference compared to controls $*: \mathrm{p}<0.05$.

Figure 3. Anogenital distance at birth and nipple retention on PND 13 in male offspring $(n=7-10)$. Mean+SEM, $* \mathrm{p}<0.05$.

Figure 4. Semen quality analysis in male 90 -day old rats exposed to $0,300,600,750$ or $900 \mathrm{mg} / \mathrm{kg}$ bw per day of DINP from GD 7 to PND 17 (n=6-10). Mean+SEM, * $\mathrm{p}<0.05$, ** $\mathrm{p}<0.01$.

Figure 5. Male and female intake of saccharin in rats exposed to $0,300,600,750$ or $900 \mathrm{mg} / \mathrm{kg}$ bw per day of DINP from GD 7 to PND 17 ( $\mathrm{n}=7-10$ litters, 1-2 animals per litter). Mean and individual observations, $* \mathrm{p}<0.05$.

Figure 6. Learning test in female rats exposed to $0,300,600,750$ or $900 \mathrm{mg} / \mathrm{kg}$ bw per day of DINP from GD 7 to PND 17 ( $\mathrm{n}=7-10$ ). Mean+SEM, * $\mathrm{p}<0.05$ compared to control females, \# $\mathrm{p}<0.05$ control males compared to control females. A dose-related reduction in swim length (A) and latency (B) to reach the platform was seen in females with the highest dose group being significantly different from control females but comparable to control males. 
Table 1. Testis histology GD 21 in rat fetuses exposed to 0, 300, 600, 750 or $900 \mathrm{mg} / \mathrm{kg}$ bw/day of DINP from GD 7 to 21 . One testis section evaluated from 1 to 4 males per litter. Table lists: \% affected, affected animals/total number of animals (affected litters/total number of litters). Results in bold are significantly different from controls in a one-sided Fisher's exact test ( $\mathrm{p} \leq 0.05)$.

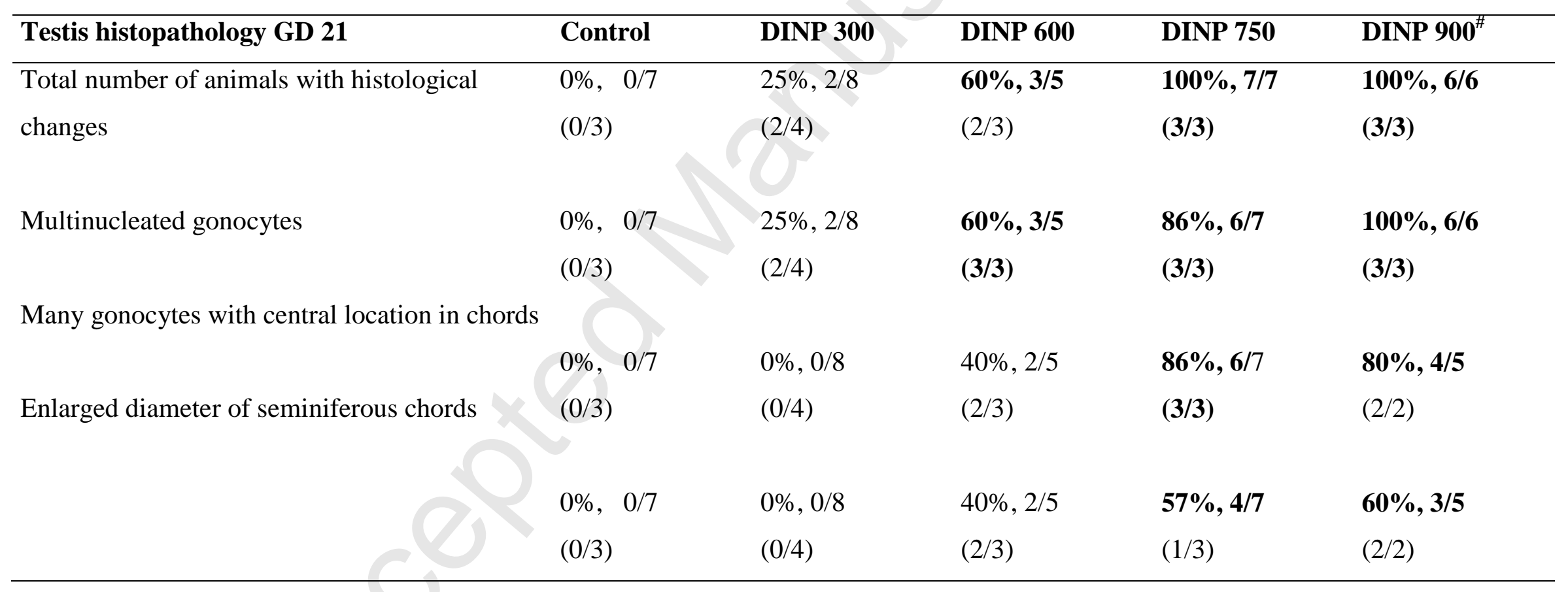

\# In one of the six animals evaluated in this group, the testis was damaged and testis histology could not be fully evaluated; however the presence of multinucleated gonocytes was noted. 
Table 2. Pregnancy data for Wistar rats exposed to DINP from GD 7 to PND 17 (mean \pm SD). No statistically significant differences between groups were observed.

\begin{tabular}{|c|c|c|c|c|c|}
\hline & Control & DINP 300 & DINP 600 & DINP 750 & DINP 900 \\
\hline Maternal bw gain, GD7-GD21 (g) & $69.56 \pm 29.2$ & $80.00 \pm 11.8$ & $75.91 \pm 23.2$ & $77.10 \pm 13.1$ & $78.17 \pm 17.2$ \\
\hline Gestation length (days) & $22.3 \pm 0.7$ & $22.3 \pm 0.5$ & $22.6 \pm 0.5$ & $22.3 \pm 0.9$ & $22.3 \pm 0.5$ \\
\hline No. of Fetuses & 80 & 77 & 99 & 84 & 90 \\
\hline No. of Litters & 9 & 9 & 10 & 9 & 10 \\
\hline Maternal body weight & $233.9 \pm 10.6$ & $234.6 \pm 13.7$ & $231.7 \pm 7.6$ & $236.4 \pm 7.0$ & $224.5 \pm 12.0$ \\
\hline No. Implantations & $10.1 \pm 4.6$ & $10.1 \pm 1.1$ & $11.5 \pm 1.8$ & $10.4 \pm 3.7$ & $11.0 \pm 2.7$ \\
\hline No. live fetuses & $8.9 \pm 4.9$ & $8.6 \pm 2.4$ & $9.9 \pm 2.3$ & $9.3 \pm 3.7$ & $9.0 \pm 3.5$ \\
\hline$\%$ post-implantation loss & $23.0 \pm 31.5$ & $14.7 \pm 16.9$ & $13.8 \pm 16.1$ & $10.1 \pm 10.0$ & $18.7 \pm 20.5$ \\
\hline Males in $\%$ of total & $45.5 \pm 21.5$ & $42.3 \pm 21.3$ & $55.2 \pm 22.9$ & $38.1 \pm 15.5$ & $48.9 \pm 28.2$ \\
\hline
\end{tabular}


Table 3. Body weights, anogenital distance at birth (AGD) and nipple retention on PND 13 for pups exposed to DINP from GD 7 to PND 17 (mean $\pm \mathrm{SD})$.

\begin{tabular}{|c|c|c|c|c|c|}
\hline Males & Control & DINP 300 & DINP 600 & DINP 750 & DINP 900 \\
\hline Birth weight $^{\mathrm{a}}(\mathrm{g})$ & $6.39 \pm 0.39$ & $6.30 \pm 0.12$ & $6.12 \pm 0.32$ & $6.14 \pm 0.49$ & $6.00 \pm 0.56$ \\
\hline Weight PND $13^{\mathrm{a}}(\mathrm{g})$ & $28.64 \pm 5.21$ & $28.60 \pm 2.99$ & $27.44 \pm 2.25$ & $26.25 \pm 3.58$ & $25.57 \pm 2.96$ \\
\hline $\mathrm{AGD}^{\mathrm{a}}$ (units) & $21.50 \pm 1.82$ & $21.09 \pm 1.58$ & $20.65 \pm 2.11$ & $20.67 \pm 1.55$ & $19.89 \pm 1.39 *$ \\
\hline $\mathrm{AGDi}^{\mathrm{b}}$ (units) & $11.60 \pm 1.04$ & $11.43 \pm 0.82$ & $11.31 \pm 0.20$ & $11.29 \pm 0.75$ & $11.01 \pm 0.88 *$ \\
\hline Nipples & $1.98 \pm 0.83$ & $2.00 \pm 0.64$ & $2.91 \pm 0.69^{c}$ & $3.14 \pm 1.21 *$ & $3.17 \pm 0.92 *$ \\
\hline \multicolumn{6}{|l|}{ Females } \\
\hline Birth weight $^{\mathrm{a}}(\mathrm{g})$ & $5.97 \pm 0.31$ & $5.90 \pm 0.19$ & $6.01 \pm 0.32$ & $5.88 \pm 0.41$ & $5.76 \pm 0.29$ \\
\hline Weight PND $13^{\mathrm{a}}(\mathrm{g})$ & $29.49 \pm 4.69$ & $27.93 \pm 2.53$ & $26.47 \pm 2.49$ & $24.40 \pm 4.62 *$ & $24.67 \pm 3.19^{d}$ \\
\hline $\mathrm{AGD}^{\mathrm{a}}$ (units) & $11.05 \pm 0.90$ & $11.32 \pm 0.85$ & $11.38 \pm 1.30$ & $11.27 \pm 0.86$ & $10.70 \pm 0.66$ \\
\hline $\mathrm{AGDi}^{\mathrm{b}}$ (units) & $6.10 \pm 0.50$ & $6.27 \pm 0.48$ & $6.26 \pm .0 .67$ & $6.25 \pm 0.38$ & $5.98 \pm 0.41$ \\
\hline Nipples & $12.30 \pm 0.26$ & $12.25 \pm 0.19$ & $12.3 \pm 0.24$ & $12.24 \pm 0.14$ & $12.34 \pm 0.25$ \\
\hline
\end{tabular}

${ }^{a}$ Analyzed with body weight as a covariate

${ }^{\mathrm{b}}$ AGDi is defined as AGD divided by the cube root of the body weight

*ANOVA followed by Dunnett's test $p<0.05$. **ANOVA followed by Dunnett's test $p<0.01$

${ }^{\mathrm{c}}$ ANOVA followed by Dunnett's test $p=0.058,{ }^{\mathrm{d}}$ ANOVA followed by Dunnett's test $p=0.052$ 
Table 4. Body weights, organ weights, anogenital distance (AGD) and testosterone levels in 90-day-old rats exposed to 0, 300, 600, 750 or $900 \mathrm{mg} / \mathrm{kg}$ bw/day of DINP from GD 7 to PND 17. Serum Inhibin B levels in 22 day old rats. Body and organ weights are in grams and anogenital distance in $\mathrm{cm}$. No statistically significant differences between groups were observed. For males n= 6-10 litters per group, 1-7 males per litter (18-35 males per group). For females n= 6-8 litters, 1-2 females per litter (10 to 14 females per group).

\begin{tabular}{|c|c|c|c|c|c|c|c|c|c|c|}
\hline \multirow{2}{*}{$\begin{array}{l}\text { Males } \\
\text { Body wt }\end{array}$} & \multicolumn{2}{|c|}{ Control } & \multicolumn{2}{|c|}{ DINP 300} & \multicolumn{2}{|c|}{ DINP 600} & \multicolumn{2}{|c|}{ DINP 750} & \multicolumn{2}{|c|}{ DINP 900} \\
\hline & 374.70 & \pm 28.26 & 378.53 & \pm 29.45 & 389.91 & \pm 28.90 & 368.17 & \pm 32.56 & 367.50 & \pm 25.45 \\
\hline Liver & 11.96 & \pm 1.14 & 12.46 & \pm 1.17 & 12.92 & \pm 1.27 & 11.71 & \pm 1.27 & 11.42 & \pm 0.92 \\
\hline Kidney & 2.21 & \pm 0.16 & 2.18 & \pm 0.22 & 2.17 & \pm 0.23 & 2.19 & \pm 0.28 & 2.14 & \pm 0.17 \\
\hline Adrenals & 0.058 & \pm 0.009 & 0.052 & \pm 0.007 & 0.051 & \pm 0.008 & 0.058 & \pm 0.010 & 0.051 & \pm 0.009 \\
\hline Thyroid & 0.021 & \pm 0.008 & 0.026 & \pm 0.018 & 0.020 & \pm 0.005 & 0.028 & \pm 0.016 & 0.022 & \pm 0.014 \\
\hline Right testis & 1.85 & \pm 0.21 & 1.84 & \pm 0.16 & 1.92 & \pm 0.17 & 1.78 & \pm 0.11 & 1.85 & \pm 0.14 \\
\hline Left testis & 1.87 & \pm 0.18 & 1.86 & \pm 0.17 & 1.90 & \pm 0.34 & 1.82 & \pm 0.13 & 1.92 & \pm 0.20 \\
\hline Left epidididymis & 0.58 & \pm 0.04 & 0.56 & \pm 0.04 & 0.58 & \pm 0.08 & 0.55 & \pm 0.05 & 0.58 & \pm 0.04 \\
\hline Prostate & 0.50 & \pm 0.11 & 0.50 & \pm 0.08 & 0.51 & \pm 0.10 & 0.48 & \pm 0.10 & 0.44 & \pm 0.08 \\
\hline LABC & 1.03 & \pm 0.09 & 1.01 & \pm 0.07 & 0.97 & \pm 0.10 & 0.97 & \pm 0.11 & 0.96 & \pm 0.10 \\
\hline Bulbourethral gland & 0.11 & \pm 0.02 & 0.12 & \pm 0.03 & 0.13 & \pm 0.04 & 0.13 & \pm 0.03 & 0.11 & \pm 0.03 \\
\hline Seminal vesicle & 1.40 & \pm 0.14 & 1.30 & \pm 0.21 & 1.39 & \pm 0.22 & 1.31 & \pm 0.14 & 1.34 & \pm 0.18 \\
\hline AGD & 3.14 & \pm 0.19 & 3.15 & \pm 0.22 & 3.24 & \pm 0.20 & 3.12 & \pm 0.20 & 3.08 & \pm 0.24 \\
\hline Testis testosterone PND 90 & 43.9 & \pm 25.1 & 31.6 & \pm 19.4 & 50.3 & \pm 49.3 & 59.8 & \pm 53.6 & 27.6 & \pm 14.4 \\
\hline Serum inhibin B PND 22 & 126 & \pm 37 & 123 & \pm 36 & 129 & \pm 70 & 111 & \pm 30 & 120 & \pm 44 \\
\hline \multicolumn{11}{|l|}{ Females } \\
\hline Body wt & 213.9 & \pm 9.73 & 236.54 & \pm 35.56 & 232.29 & \pm 23.16 & 218.58 & \pm 16.33 & 218.09 & \pm 17.43 \\
\hline Ovary & 0.092 & \pm 0.011 & 0.101 & \pm 0.018 & 0.100 & \pm 0.021 & 0.093 & \pm 0.012 & 0.108 & \pm 0.019 \\
\hline Uterus & 0.466 & 0.081 & 0.501 & \pm 0.093 & 0.488 & \pm 0.050 & 0.503 & \pm 0.044 & 0.485 & \pm 0.031 \\
\hline
\end{tabular}


Table 5. Histology of male reproductive organs at PND 90 in rats exposed to 0, 300, 600, 750 or $900 \mathrm{mg}$ DINP/kg bw/day from GD 7 to PND 17. No significant differences between controls and DINP exposed groups were observed. Table lists: \% affected, affected animals/total number of animals (the listed total number of animals examined represents 6 to 10 litters per group). No dose-related changes were observed on PND 90.

\begin{tabular}{|c|c|c|c|c|c|}
\hline Histopathology PND 90 & Control & DINP 300 & DINP 600 & DINP 750 & DINP 900 \\
\hline \multicolumn{6}{|l|}{ Seminal vesicle } \\
\hline Total number of animals with histological changes & $6 \%, 1 / 17$ & $0 \%$ & $0 \%$ & $8 \%, 1 / 13$ & $0 \%$ \\
\hline Remains of epithelial cells in lumen of coagulating & $6 \%, 1 / 17$ & $0 \%$ & $0 \%$ & $0 \%$ & $0 \%$ \\
\hline gland & $0 \%$ & $0 \%$ & $0 \%$ & $8 \%, 1 / 13$ & $0 \%$ \\
\hline
\end{tabular}

\section{Prostate}

Total number of animals with histological changes

$\begin{array}{rrrrr}33 \%, 6 / 18 & 44 \%, 7 / 16 & 44 \%, 7 / 16 & 54 \%, 7 / 13 & 29 \%, 4 / 14 \\ 17 \%, 3 / 18 & 13 \%, 2 / 16 & 19 \%, 3 / 16 & 8 \%, 1 / 13 & 0 \% \\ 22 \%, 4 / 18 & 25 \%, 4 / 16 & 31 \%, 5 / 16 & 38 \%, 5 / 13 & 21 \%, 3 / 14 \\ 0 \% & 6 \%, 1 / 16 & 6 \%, 1 / 16 & 23 \%, 3 / 13 & 0 \% \\ 6 \%, 1 / 18 & 0 \% & 13 \%, 2 / 16 & 15 \%, 2 / 13 & 0 \% \\ 6 \%, 1 / 18 & 13 \%, 2 / 16 & 13 \%, 2 / 16 & 15 \%, 2 / 13 & 7 \%, 1 / 14\end{array}$

Leucocyte infiltration within acini

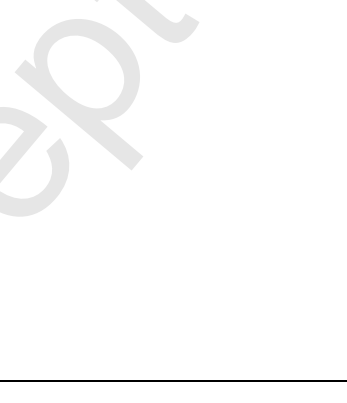

\section{Testis}

Total number of animals with histological changes

Generalized or focal degeneration (>10\% affected)

$\begin{array}{rrrrr}30 \%, 7 / 23 & 26 \%, 5 / 19 & 29 \%, 10 / 35 & 11 \%, 2 / 18 & 6 \%, 1 / 18 \\ 0 \% & 0 \% & 0 \% & 0 \% & 0 \% \\ 9 \%, 2 / 23 & 0 \% & 9 \%, 3 / 35 & 0 \% & 0 \% \\ 22 \%, 5 / 23 & 26 \%, 5 / 19 & 20 \%, 7 / 35 & 11 \%, 2 / 18 & 6 \%, 1 / 18\end{array}$

Malformed tubules in small Leydig cell clusters

Single tubules containing no spermatids

$22 \%, 5 / 23 \quad 26 \%, 5 / 19$

$20 \%, 7 / 35$

$11 \%, 2 / 18$

$6 \%, 1 / 18$ 

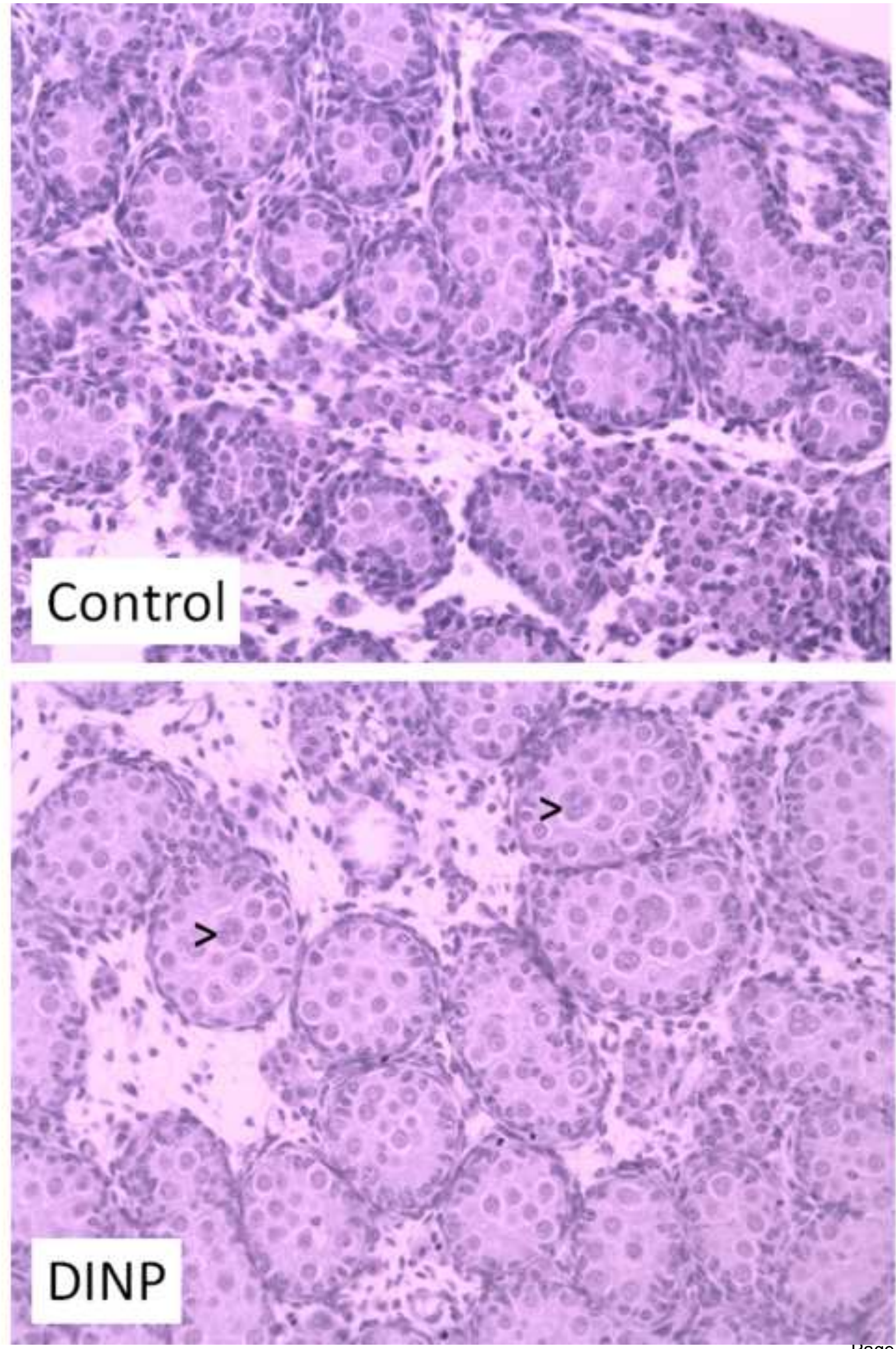


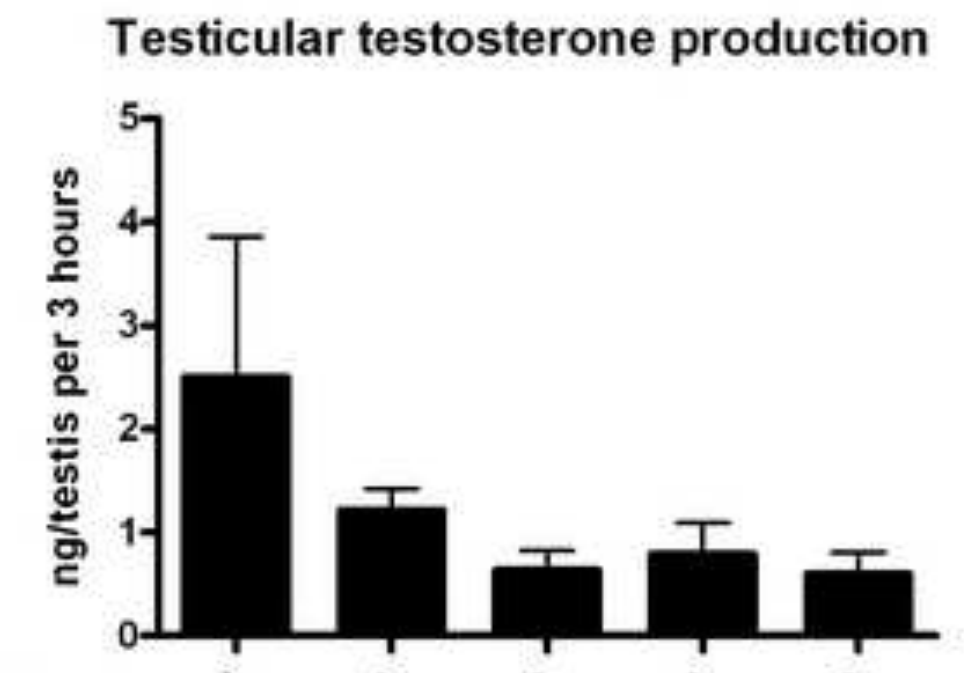

A)

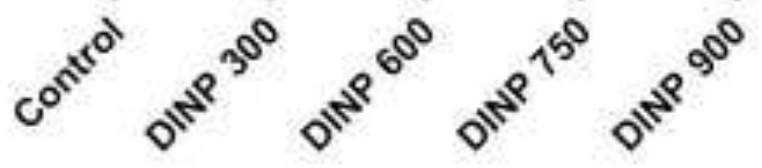

Plasma testosterone

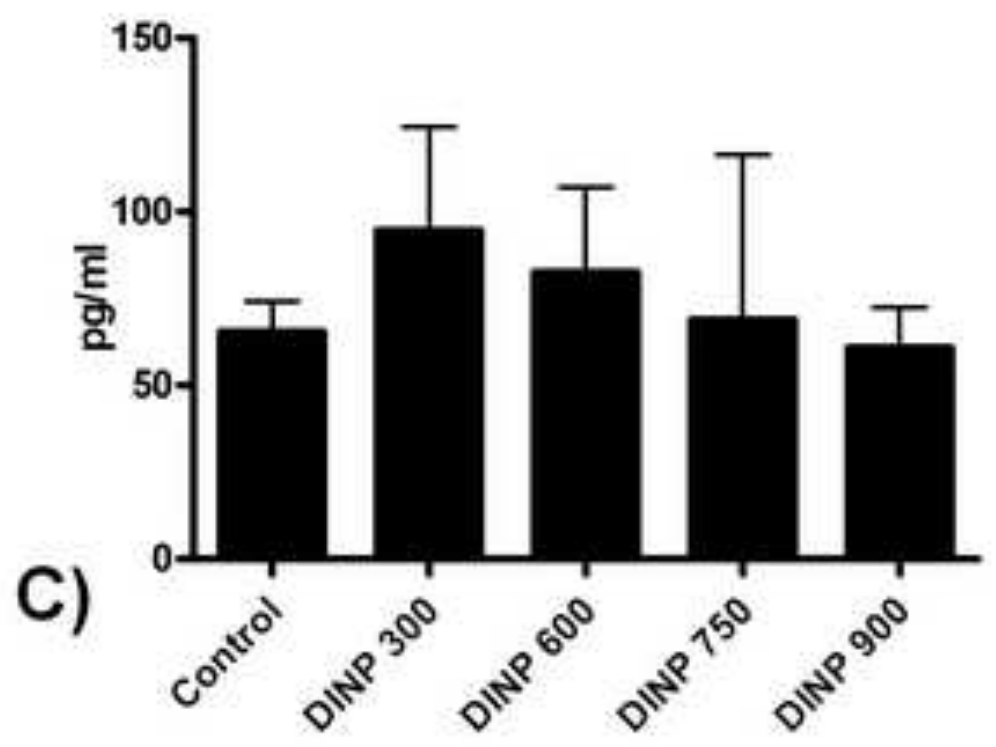

Testicular testosterone content

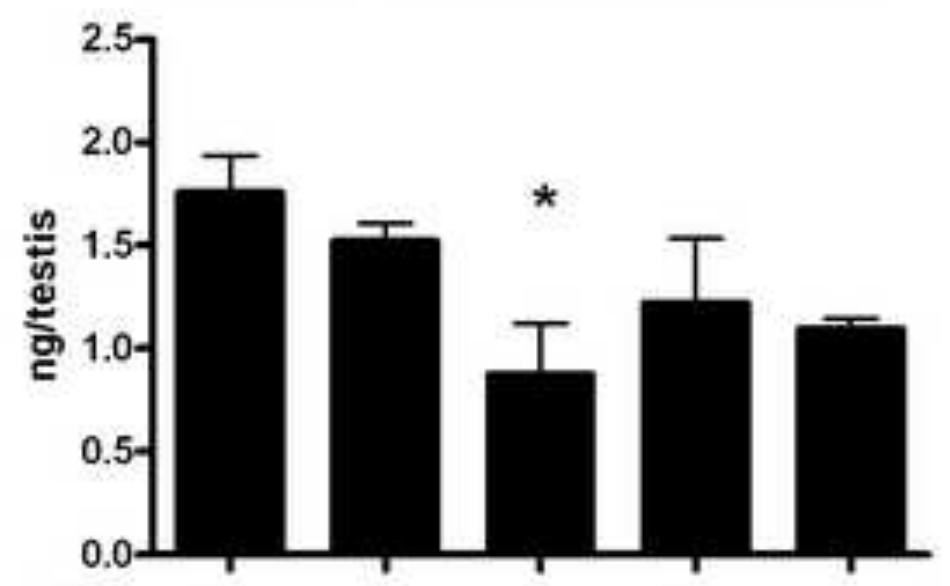

B)

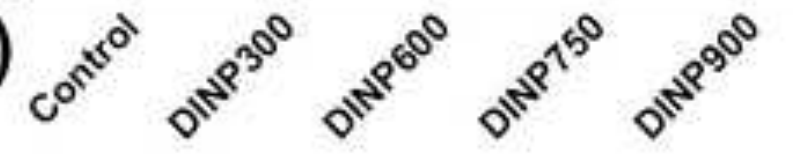

Plasma LH

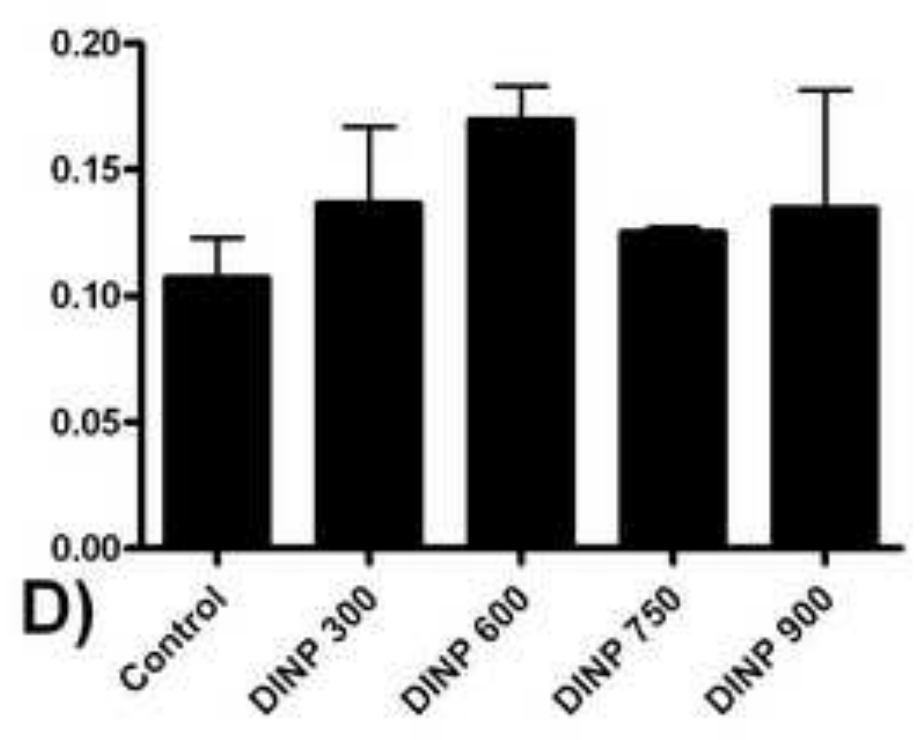


AGD males

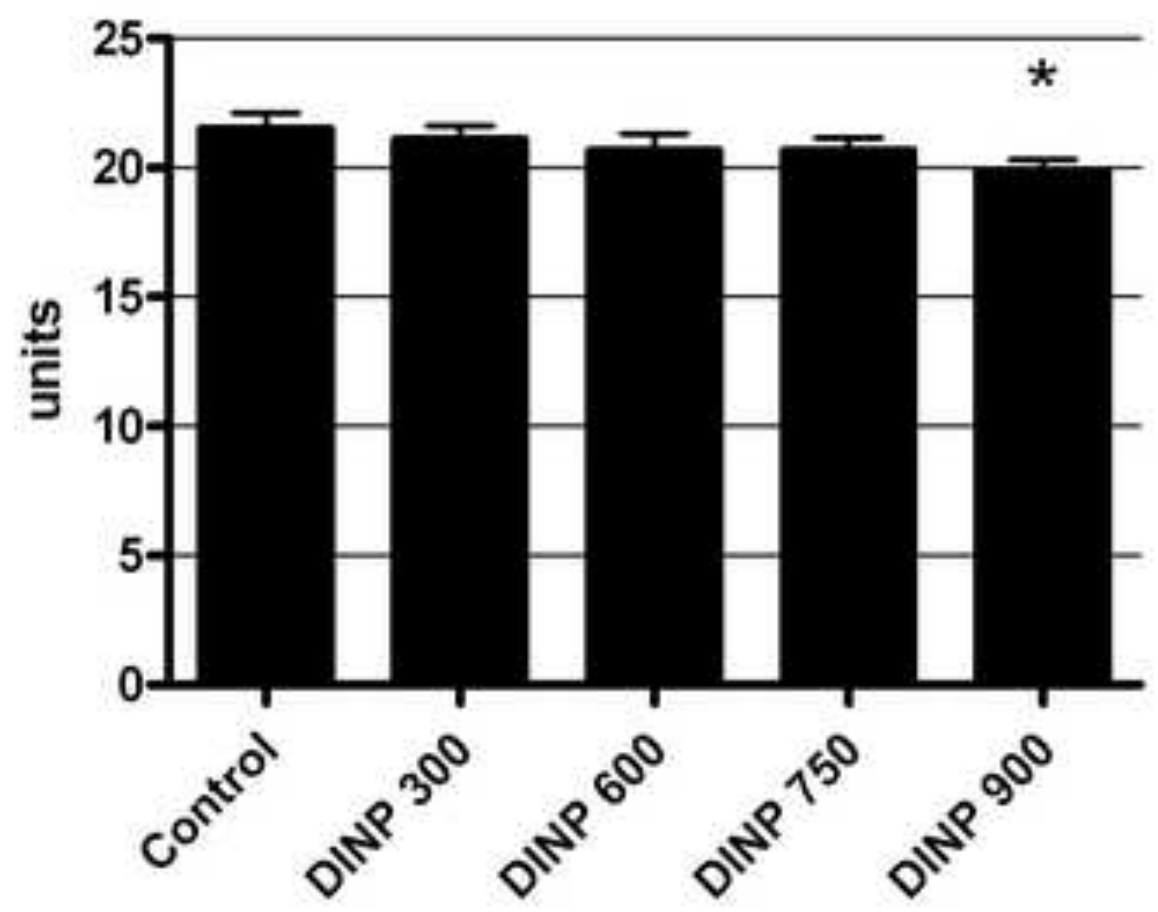

Nipple retention males

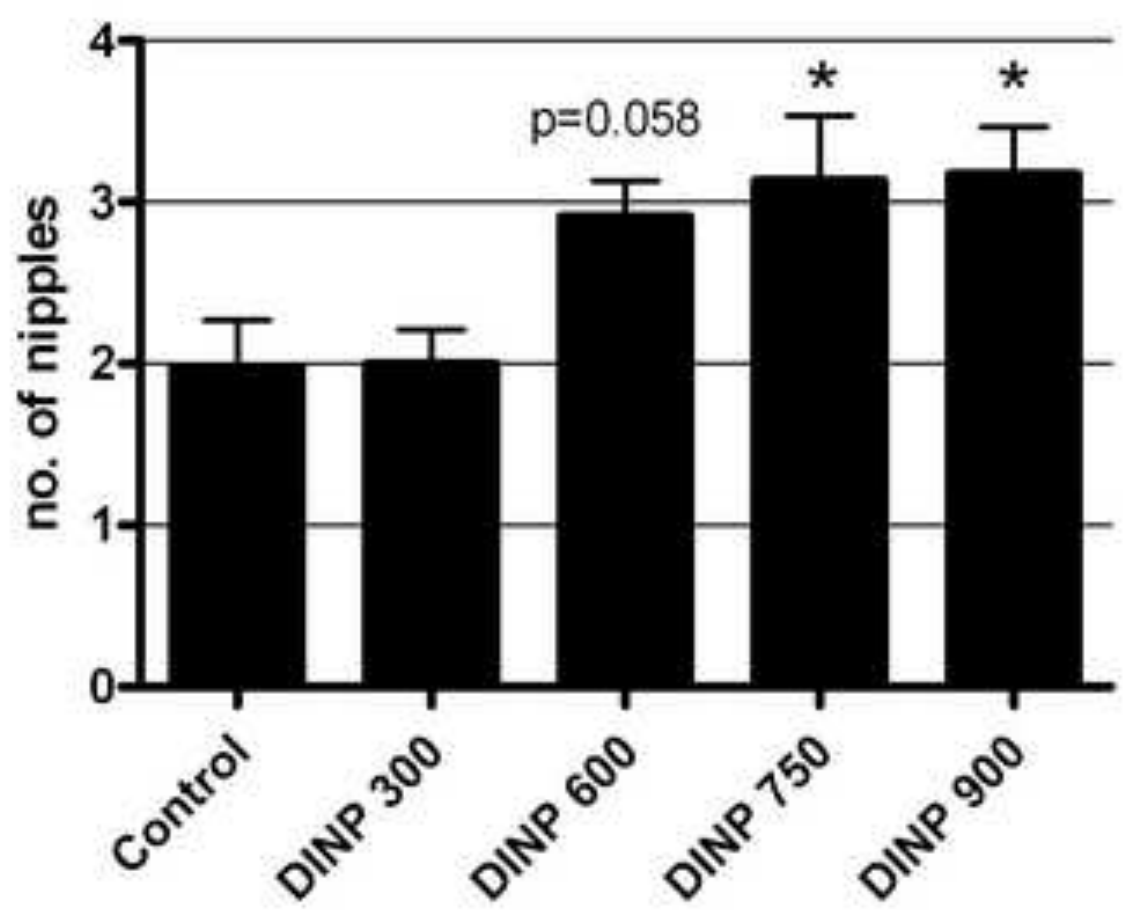




\section{Figure 4}

Click here to download high resolution image

Sperm motility

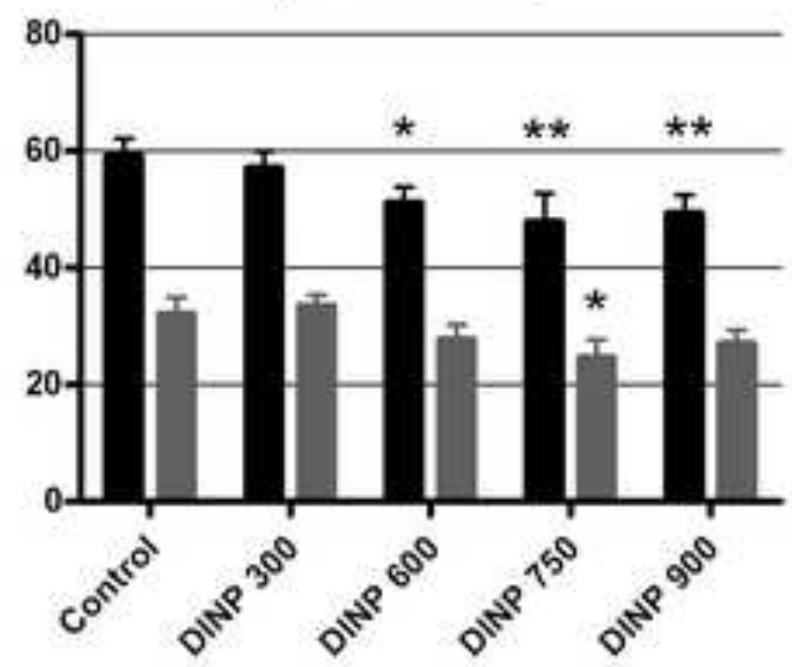

Sperm count

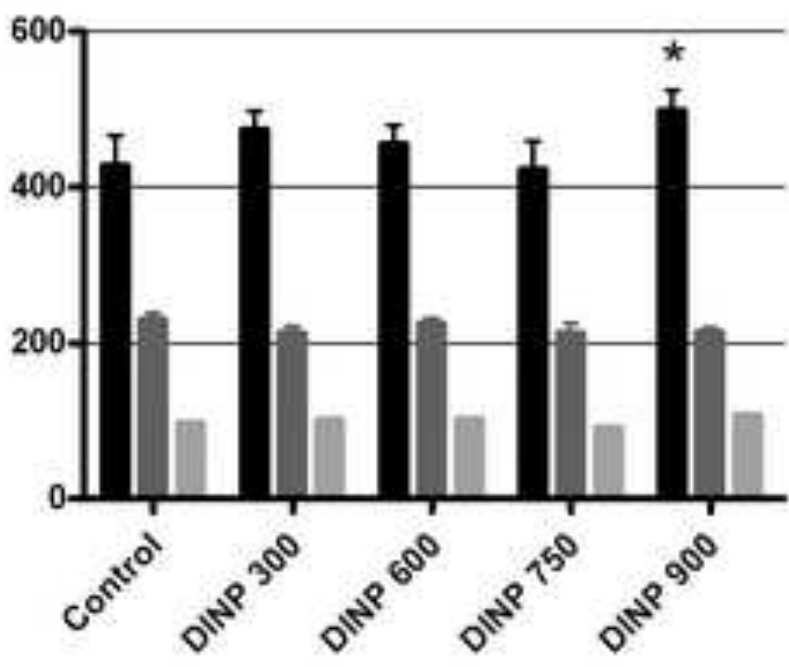

Velocity

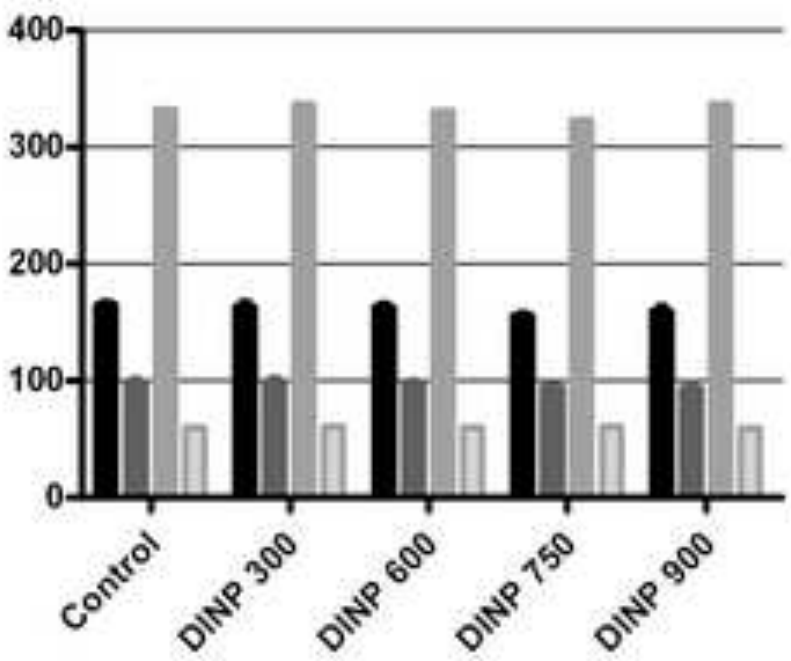

$\%$ Motile sperm

$\%$ Progressive sperm
Sperm/g cauda

Cauda epid wt (mg)

Sperm count
Average path $\mathrm{v}$.

Straight line v.

Curviliniar $\mathrm{v}$.

Straightness 


\section{Saccharin intake}

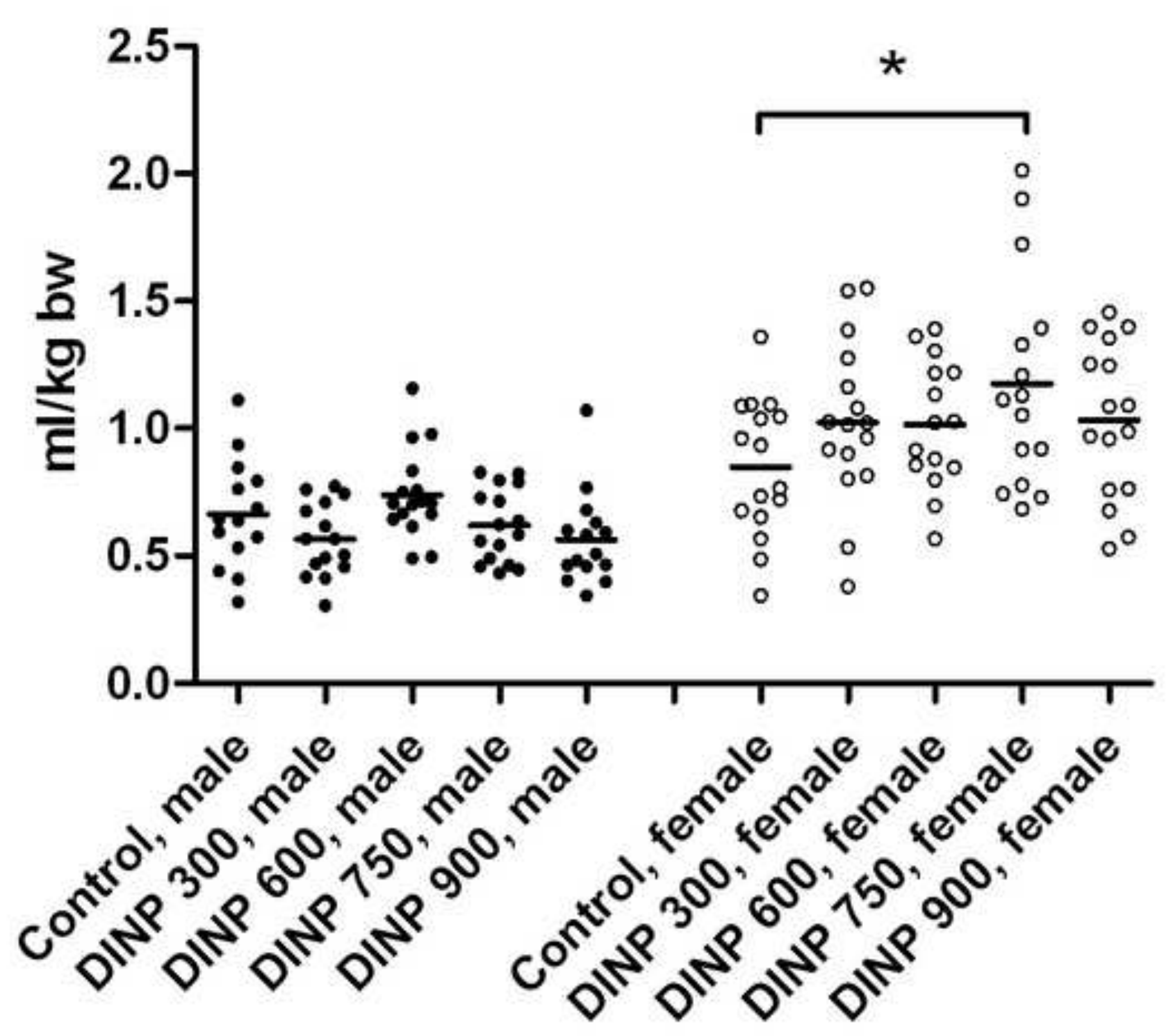


Morris Water Maze learning test, swim length
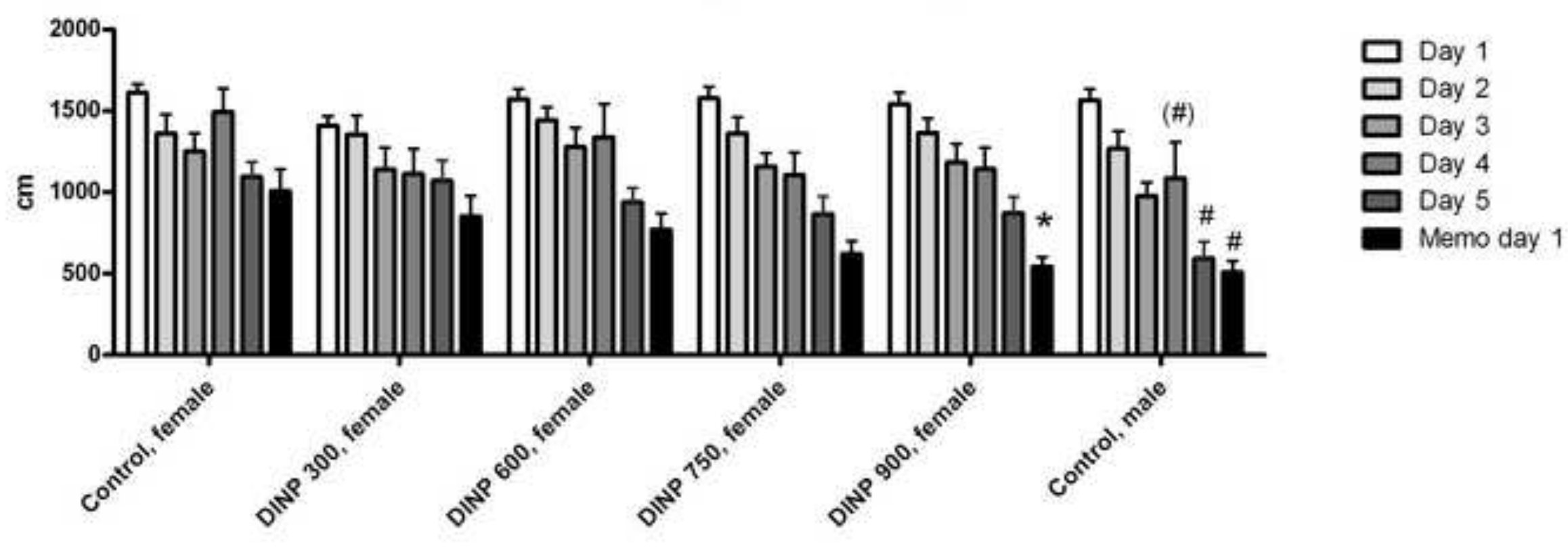

Morris Water Maze learning test, latency
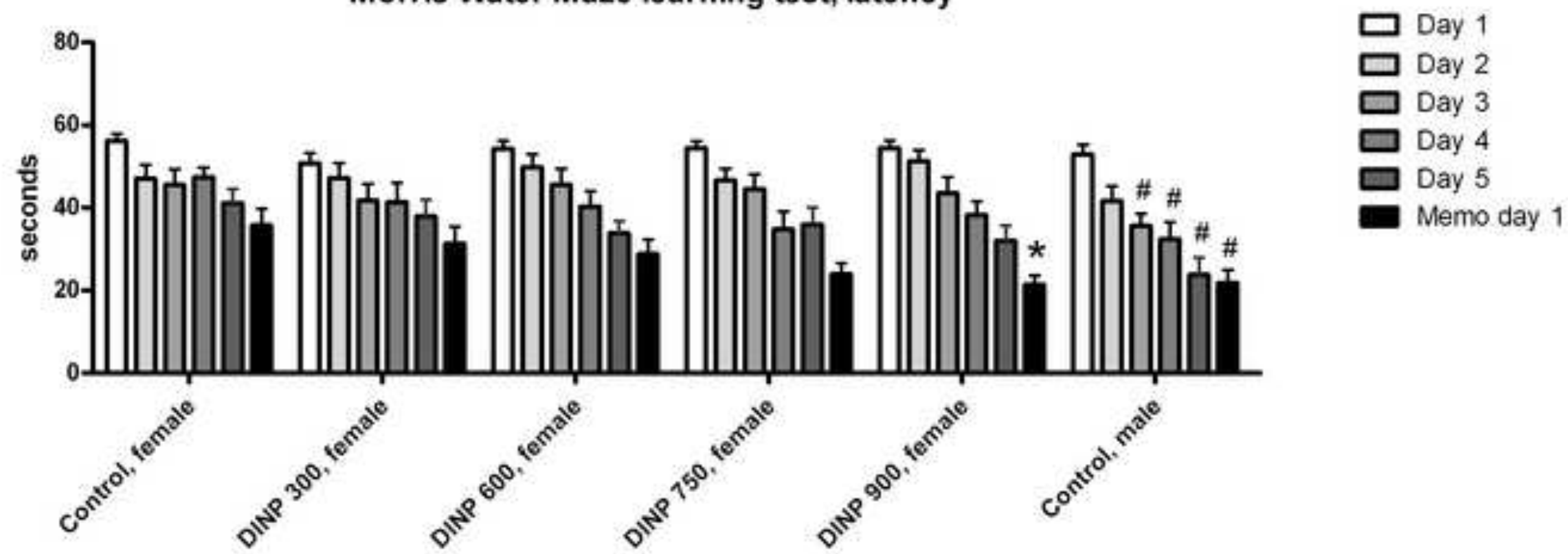